\title{
A bi-objective programming model for carbon emission quota allocation: Evidence from the Pearl River Delta region
}

\author{
Lixu Li ${ }^{\text {a }}$, Fei Ye ${ }^{\text {a,* }}$, Yina $\mathrm{Li}^{\text {a,* }}$, Kim Hua Tan ${ }^{\mathrm{b}}$
}

a School of Business Administration, South China University of Technology, Guangzhou, 510640, China

b Operations Management and Information Systems Division, Nottingham University, Business School, United Kingdom

* Corresponding author.

E-mail addresses: yefei@scut.edu.cn (F. Ye), bmliyina@scut.edu.cn (Y. Li). 


\title{
A bi-objective programming model for carbon emission quota allocation: Evidence from the Pearl River Delta region
}

\begin{abstract}
As a core component of the emission trading scheme (ETS), the initial allocation of carbon quotas is extremely important. Currently, most allocation methods mainly focus on the realization of a single performance goal, which will result in conflicts between different levels of participants. To overcome this deficiency, this paper develops a bi-objective programming model (BPM) with two sub-objective functions of abatement costs and carbon assets.
\end{abstract} Meanwhile, cost-oriented model (CM) and asset-oriented model (AM) are implemented as comparison approaches that represent the minimization of regional abatement costs and the maximization of individual interests, respectively. The empirical results of the Pearl River Delta (PRD) region reveal that BPM is the most efficient and feasible approach to some extent. More precisely, BPM can motivate the enthusiasm of all participants while optimizing abatement costs. With the increase of regional total quotas, the advantage of BPM becomes more and more prominent. The contribution of this paper is to present a novel method for carbon emission quota allocation, which fills the gap in the existing literature. Furthermore, the proposed method that can be deployed in other similar regions assists policymakers in enacting an effective emission reduction policy and in better understanding the objectives of economy, energy and environment.

Keywords: Carbon emission quota allocation; Bi-objective programming model; Cost-oriented model; Asset-oriented model; Pearl River Delta 


\begin{tabular}{|c|c|c|c|}
\hline \multicolumn{4}{|c|}{ Nomenclature } \\
\hline \multicolumn{2}{|c|}{ Abbreviations } & \multicolumn{2}{|c|}{ Latin symbols } \\
\hline ADF & Augmented Dickey-Fuller & $A$ & Abatement volume (tons) \\
\hline $\mathrm{AM}$ & Asset-oriented Model & $C I$ & Carbon intensity (ton $/ 10^{4}$ Yuan) \\
\hline BPM & Bi-objective Programming Model & $E C$ & $\begin{array}{l}\text { Energy consumption }\left(10^{4} \text { tons of }\right. \\
\text { standard coal) }\end{array}$ \\
\hline BSGP & $\begin{array}{l}\text { Bureau of Statistics of Guangdong } \\
\text { Province }\end{array}$ & $G D P$ & $\begin{array}{l}\text { Gross Domestic Product } \\
\left(10^{8} \text { Yuan }\right)\end{array}$ \\
\hline CCTN & China Carbon Trading Network & $M A C$ & $\begin{array}{l}\text { Marginal Abatement Costs (Yuan/ } \\
\text { ton) }\end{array}$ \\
\hline $\mathrm{CM}$ & Cost-oriented Model & $p$ & Carbon price (Yuan/ton) \\
\hline $\mathrm{CO}_{2}$ & Carbon dioxide & $Q$ & Quotas (tons) \\
\hline $\mathrm{CSC}$ & China State Council & $R^{2}$ & Goodness of Fit \\
\hline $\mathrm{EKC}$ & Environmental Kuznets Curve & $R$ & National abatement rate $(\%)$ \\
\hline EROI & Energy Return on Investment & $r$ & Abscissa \\
\hline ETS & Emission Trading Scheme & $T A C$ & Total Abatement Costs $\left(10^{4}\right.$ Yuan $)$ \\
\hline $\begin{array}{l}\text { EU } \\
\text { ETS }\end{array}$ & $\begin{array}{l}\text { European Union Emissions Trading } \\
\text { System }\end{array}$ & $V$ & Carbon assists $\left(10^{4}\right.$ Yuan $)$ \\
\hline IPCC & $\begin{array}{l}\text { Intergovernmental Panel on Climate } \\
\text { Change }\end{array}$ & & \\
\hline MAPE & Mean Absolute Percentage Error & Subsc & ripts/Superscript \\
\hline MCDA & Multi-criteria Decision Analysis & base & Base year \\
\hline NBSC & $\begin{array}{l}\text { National Bureau of Statistics of } \\
\text { China }\end{array}$ & $i$ & Participant's number \\
\hline OLS & Ordinary Least Square & $l$ & Lower bound \\
\hline PRD & Pearl River Delta & $t$ & Year \\
\hline UNDP & $\begin{array}{l}\text { United Nations Development } \\
\text { Programme }\end{array}$ & $u$ & Upper bound \\
\hline \multicolumn{4}{|c|}{ Greek symbols } \\
\hline$\mu$ & Regional abatement rate $(\%)$ & & \\
\hline
\end{tabular}




\section{Introduction}

With the development of industrialization and urbanization, carbon dioxide $\left(\mathrm{CO}_{2}\right)$ emissions have risen sharply during the past decade (IPCC, 2014). To maintain the worldwide sustainable development, various organizations and countries have enacted relevant laws and regulations to limit $\mathrm{CO}_{2}$ emissions (Zhou et al., 2017a; UNDP, 2015). Among the three major regulation policy tools including emission trading scheme (ETS), administrative order policy and carbon tax, ETS is regarded as the most economical and effective mechanism (Liu et al., 2015; Sartor et al., 2014). China, the largest $\mathrm{CO}_{2}$ emitter, is preparing to establish a unified national ETS by the end of 2017 (Xia and Tang, 2017). Once the unified national ETS is completed, China will surpass the European Union Emissions Trading System (EU ETS) to become the largest ETS in the world (Zhao et al., 2017).

As a core element of the ETS, the initial allocation of carbon quotas is extremely important. Currently, the main allocation methods for China's ETS in practice are grandfathering derived from historical carbon emissions and benchmarking derived from industrial average carbon emissions (Ji et al., 2017). However, both of the above methods have some drawbacks. For example, grandfathering cannot cover the new capacity of enterprises (Fan et al., 2016), while the standard of benchmarking is difficult to determine because of data shortage (Liu et al., 2015). Therefore, how to design a suitable allocation method tailored to the real circumstance has become a huge task for the Chinese government.

To optimize the initial allocation of carbon quotas, many scholars have explored different allocation methods in theory, including indicator approach, optimization model, game model and hybrid methods (Zhou and Wang, 2016). Based on different equality perspectives, historical 
carbon emissions, population, GDP/per capita GDP are usually selected as indicators that represent the principles of sovereignty/grandfathering, egalitarianism and ability to pay/ economic activity, respectively (Zhou et al., 2013; Zhao et al., 2010; Phylipsen et al., 1998). Combining different principles together, multi-criteria decision analysis (MCDA) that is dominated by information entropy method (Li et al., 2018; Qin et al., 2017) has become the mainstream of the composite indicator approach. However, the composite indicator approach cannot reflect the specific goal that policymakers want to achieve, nor does it have a uniform standard to determine the weight of each indicator (Zhou and Wang, 2016). Consequently, optimization model and game model are developed.

With respect to optimization model, efficiency and abatement costs are two conventional optimization goals. To maximize allocation efficiency, Zeng et al. (2016) allocated carbon quotas among 30 provinces in China by hiring a ZSG-DEA model with fixed carbon emissions and non-fossil energy consumption. Zhang and Hao (2017) also applied an input-oriented ZSGDEA model, but their allocation was built on the industry level. With the aim of reducing abatement costs, Fan et al. (2016) simulated the marginal emission abatement cost curve of China in 2015 and 2020 with a CHINAGEM model and calculated the equilibrium carbon price. Liu and Lin (2017) estimated the marginal emission abatement cost curves by a parametric directional output distance functions and proposed a novel nonlinear programming model in China's building construction industry. In terms of game model, the Shapley value method is the most common method in empirical research. Zhang et al. (2014) adopted the gravity model to calculate the regional connection and assigned initial quotas using the Shapley value method. Liao et al. (2015) further compared the discrepancies among the Shapley value method, 
grandfathering and benchmarking, and pointed out that the Shapley value method was considered to be a theoretical equity reference. However, because the Shapley value method is an alliance cooperation game (Chang et al., 2016), it will lead to unfairness if the participants of ETS are different types of enterprises. Furthermore, the marginal profit of each participant is difficult to ascertain. Therefore, the Shapley value method is only for reference and has less available in practice. Finally, some methods (e.g., Zhou et al., 2017b) that combine multiple groups of the above methods together can be regarded as the hybrid methods.

Although the above literature provides unique ideas for the allocation of carbon quotas, most of them mainly focus on a single performance goal, such as realizing fairness allocation (Chen et al., 2016), minimizing abatement costs (Liu and Lin, 2017) and maximizing profits (Liao et al., 2015) or efficiency (Zhang and Hao, 2017). However, different performance goals sometimes are incongruous or even contradictory (Salehi et al., 2017). For example, sovereignty principle and ability to pay principle, egalitarianism principle and economic activity principle, as well as minimizing abatement costs and maximizing efficiency. Consequently, carbon emission quota allocation is not an isolated process for achieving a single performance goal, it should be a comprehensive process in which all levels of participants work together and reach a consensus. Remarkably, there are two significant factors that cannot be overlooked among various performance goals. One is the cost factor (i.e., abatement costs) that is the purpose of the existence of ETS (Fan et al., 2016), and the other is the enthusiasm of the participants (i.e., individual interests) that is the basis for the operation of ETS (Liu et al., 2015). However, these two factors sometimes will create conflicts because the clean participants usually have a higher economic level, while the dirty participants often locate in developing 
stage. Therefore, the purpose of this paper is to find a balance between overall interests (i.e., social abatement costs) and individual interests, so as to realize an effective and feasible allocation of carbon quotas.

Technically, this paper develops a bi-objective programming model (BPM) with two subobjective functions of abatement costs and carbon assets. Meanwhile, cost-oriented model (CM) and asset-oriented model (AM) are applied as comparison approaches, which represent the minimization of social abatement costs and the maximization of individual interests, respectively. To verify the validity of the proposed method, this paper selects the Pearl River Delta (PRD) region where the intraregional development is extremely imbalanced as a representative example. The empirical results show that BPM is the most efficient and feasible approach to some extent, because the allocation of BPM is a non-inferior solution (Hombach and Walther, 2015) that can achieve a trade-off between overall interests and individual interests. In general, this paper presents a novel method for carbon emission quota allocation, which fills the gap in the existing literature. Simultaneously, the proposed method that can be implemented in other similar regions assists policymakers in enacting an effective emission reduction policy and in better understanding the objectives of economy, energy and environment.

The layout of this paper is shown as follows: Section 2 introduces the general framework and methodology. Section 3 presents the situation and data sources of the PRD region. Section 4 discusses the allocation results using different approaches. Section 5 provides a sensitivity analysis of changes in regional total quotas. Section 6 summarizes the conclusions and proposes some policy implications. 


\section{Methodology}

\subsection{Research framework}

Fig. 1 shows the general framework of this paper. Firstly, based on the previous literature, this paper reviews two traditional allocation approaches and proposes a novel approach. Secondly, the grey system model and the Environmental Kuznets Curve (EKC) are taken to determine the bounds of initial quotas, and scenario analysis is used to predict GDP in 2020 . Thirdly, because of the imbalanced development of the region, the PRD region is chosen as a representative example to reflect the discrepancies among different allocation approaches. Fourthly, to demonstrate the advantages of the proposed method, BPM is compared with CM and AM that represent overall interests and individual interests, respectively. Lastly, according to the comparison results and sensitivity analysis, several policy implications for improving the performance of pilot work and measurements for emission reduction are provided.

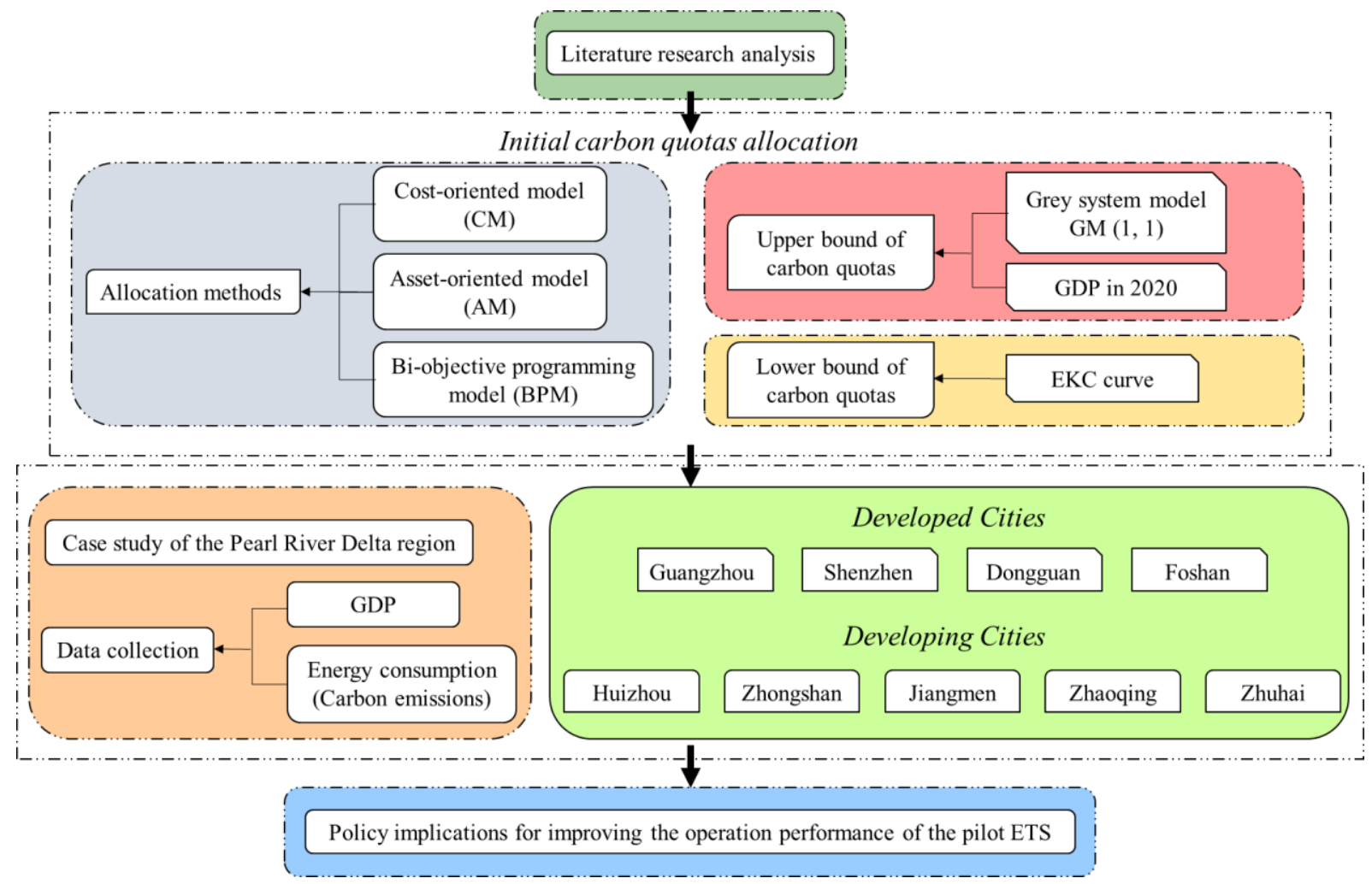

Fig. 1. The general framework of carbon emission quota allocation 


\subsection{Quota allocation by CM}

It is assumed that there are $n$ participants (e.g., cities or enterprises) within a regional ETS, and the initial carbon quotas for these participants are freely available. According to the provision of the central government, the initial regional total quotas for the target year (i.e., 2020) are,

$$
\begin{gathered}
C I_{i t}=\frac{Q_{i t}}{G D P_{i t}}, i=1,2,3, \ldots, n \\
C I_{\text {base }}=\frac{\sum_{i=1}^{n} Q_{\text {ibase }}}{\sum_{i=1}^{n} G D P_{\text {ibase }}} \\
G D P_{i 2020}=G D P_{i 2016} \times(1+\text { growth rate })^{4} \\
G D P_{2020}=\sum_{i=1}^{n} G D P_{i 2020} \\
Q_{2020}=(1-\mu) C I_{\text {base }} G D P_{2020}
\end{gathered}
$$

where $Q_{i t}, G D P_{i t}$ and $C I_{i t}$ represent the carbon emissions (quotas), Gross Domestic Product (GDP) and carbon intensity of participant $i$ in the year $t$, respectively; $C I_{\text {base }}$ is the regional carbon intensity in the base year; $\mu$ is the regional carbon intensity reduction rate. In this paper, carbon emissions (quotas) are the abbreviation of $\mathrm{CO}_{2}$ emissions (quotas).

As a cost-effective mechanism, ETS uses market instruments to encourage the participants with lower abatement costs to undertake more emission reduction tasks, while the participants with higher abatement costs must purchase quotas for completing abatement tasks (Fang et al., 2018; Xiong et al., 2017). Therefore, a reasonable allocation method should take the cost factor into account. Usually, marginal abatement costs (MAC) and total abatement costs (TAC) are two common factors that cannot be overlooked (Liu and Lin, 2017). From the regional perspective, the TACs for all participants should be minimized to realize low-cost target. To estimate the MAC and TAC of each participant in the target year (i.e., 2020), this paper follows 
the research of Fan et al. (2016) who estimated the MAC of China in 2020, as shown in Eq. (6).

$$
M A C_{2020}=-679.63 \ln (1-R)
$$

where $R$ is the abatement rate of China in 2020, and the unit of $M A C_{2020}$ is Yuan (at the 2002 constant price index) per $\mathrm{tCO}_{2}$. Because the GDP indexes from 2003 to 2005 are $114.8,114.8$ and 113.8, respectively (NBSC, 2017), the MAC of China at the 2005 constant price index can be transferred into Eq. (7). Moreover, the MAC and TAC of each participant can be obtained by coordinate translation method (Chang et al., 2016), as shown in Eqs. (8) to (10).

$$
\begin{gathered}
M A C_{i 2020}=-453.15 \ln \left(1-R_{i 2020}\right)=-453.15 \ln \left(1-\frac{A_{i 2020}}{Q_{i 2020}^{u}\left(1-r_{i}\right)}\right) \\
r_{i 2020}=1-\frac{C I_{i 2020}}{\overline{C I}_{2020}} \\
A_{i 2020}=Q_{i 2020}^{u}-Q_{i 2020} \\
T A C_{i 2020}=\int_{0}^{A_{i 2020}}\left[-453.15 \ln \left(1-\frac{x}{Q_{i 2020}^{u}\left(1-r_{i}\right)}\right)\right] d x \\
=453.15\left[Q_{i 2020}^{u}\left(1-r_{i}\right)-A_{i 2020}\right] \ln \left(1-\frac{A_{i 2020}}{Q_{i 2020}^{u}\left(1-r_{i}\right)}\right)+453.15 A_{i 2020}
\end{gathered}
$$

where $r_{i 2020}$ and $A_{i 2020}$ are the abscissa and the abatement volume of participant $i$ in 2020, respectively; the unit of $M A C_{i 2020}$ and $T A C_{i 2020}$ are Yuan (at the 2005 constant price index) per $\mathrm{tCO}_{2} ; Q_{i 2020}^{u}$ is the upper bound of participant $i$ 's carbon quotas in 2020, which is equal to the carbon emissions without policy constraint. $\overline{C I}_{2020}$ is the average carbon intensity of China in 2020 (i.e., 1.77 ton per $10^{4}$ Yuan, which can be estimated by the national emission reduction plan, namely $40 \%-45 \%$ carbon intensity will be reduced by 2020 based on the 2005 level (Liu and Lin, 2017).

To estimate $Q_{i 2020}^{u}$ for each participant, a grey system model called $\operatorname{GM}(1,1)$ is adopted due to the advantages of less required sample data, high short-term prediction accuracy and testability (Ren and $\mathrm{Gu}, 2016)$. Because the prediction of GM $(1,1)$ is based on the internal 
growth trend of the data, it can be regarded as a natural growth of carbon emissions without policy constraints. The main prediction steps of GM $(1,1)$ can be found in Ye et al. (2018)'s work. Moreover, the mean absolute percentage error $\left(M A P E_{i}\right)$ of participant $i$ can be calculated as follow:

$$
M A P E_{i}=\frac{1}{n} \sum_{j=1}^{n}\left|\frac{Q_{i}^{(0)}(\mathrm{j})-Q_{i}^{(2)}(\mathrm{j})}{Q_{i}^{(0)}(\mathrm{j})}\right| \times 100 \%
$$

where $Q_{i}^{(0)}$ and $Q_{i}^{(2)}$ are the original sequence and forecast set, respectively. $M A P E_{i}<10 \%$ means that the predication has high accuracy (Lewis, 1982).

Hence, this paper adopts a nonlinear programming model called CM to minimize the regional abatement costs, and the solution is described in Appendix A.1.

$$
\begin{gathered}
\operatorname{Min} \sum_{i=1}^{n} T A C_{i 2020} \\
\text { s.t. } \quad \sum_{i=1}^{n} Q_{i 2020} \leq Q_{2020} \\
Q_{i 2020}^{l} \leq Q_{i 2020} \leq Q_{i 2020}^{u}
\end{gathered}
$$

where $Q_{i 2020}^{l}$ is the lower bound of carbon quotas in 2020 (see Section 2.3).

\subsection{Quota allocation by AM}

With the enactment of the Kyoto protocol, the carbon emission right has become a scarce resource with tradable attributes (Li and Jia, 2017). Currently, economic development and carbon emissions cannot be decoupled significantly, and thus carbon emission space is the space for development (Fan et al., 2016). To measure the relationship between economic development and carbon emissions, EKC that considers the decreasing of carbon emissions with economic growth is wildly studied by numerous scholars (Zhao and $\mathrm{Du}, 2015$ ). Because the natural logarithmic form can reduce volatility and linearize the trend without changing the original co- 
integration relationship ( $\mathrm{Li}$ et al., 2016), this paper adopts the natural logarithmic form of EKC as described in Eq. (13).

$$
\ln Q_{i 2020}=\alpha_{i}+\beta_{1} \ln G D P_{i 2020}+\beta_{2} \ln G D P_{i 2020}^{2}+\beta_{3} \ln G D P_{i 2020}^{3}
$$

where $\alpha_{i}$ is the constant term, $\beta_{1}, \beta_{2}$ and $\beta_{3}$ are the estimated coefficients. According to Kaika and Zervas (2013)'s research, there are six forms of EKC. If $\beta_{1}>0, \beta_{2}<0$ and $\beta_{3}=$ 0 , then inverted $U$ relationship exists, indicating that carbon emissions have the highest point and the turning point can be calculated as follow:

$$
\ln G D P_{i 2020}^{*}=-\frac{\beta_{1}}{2 \beta_{2}}
$$

Song et al. (2013) had proved that the inverted U relationship of EKC existed in some regions of China, such as Guangdong (the PRD region), Hunan, Shanxi, etc. Meanwhile, the Chinese government committed to reaching the peak of carbon emissions by 2030 (CSC, 2016). Therefore, this paper assumes that the inverted $U$ relationship of EKC exists for the participants in the region. Because the promotion of economic growth is the first priority for China, carbon emissions that satisfy economic development are regarded as the lower bound of carbon quotas, namely, $Q_{i 2020}^{l}$ is calculated by Eqs. (3) and (13). Practically, the regional government will allocate slightly more initial quotas than the minimum carbon emissions to mitigate abatement pressure of each participant, and thus the value of these increment quotas is regarded as carbon assets which are defined in Eq. (15).

$$
V_{i 2020}=p I_{i 2020}=p\left(Q_{i 2020}-Q_{i 2020}^{l}\right)
$$

where $I_{i 2020}$ is the increment quotas of participant $i$ in 2020, and $p$ is the carbon price. According to Fig. 2, $p$ is assumed to be 20 Yuan per $\mathrm{tCO}_{2}$ that is the relatively stable price of Guangdong pilot ETS during the last three years (CCTN, 2017). Although carbon price is 
closely related to the number of quotas, this paper mainly focuses on the allocation of carbon quotas rather than the trading in the secondary market. Therefore, carbon assets can be considered as values corresponding to the current market price. Actually, the change of $p_{e}$ does not affect the conclusions of this paper, it only influences the relative value of $V_{i 2020}$.

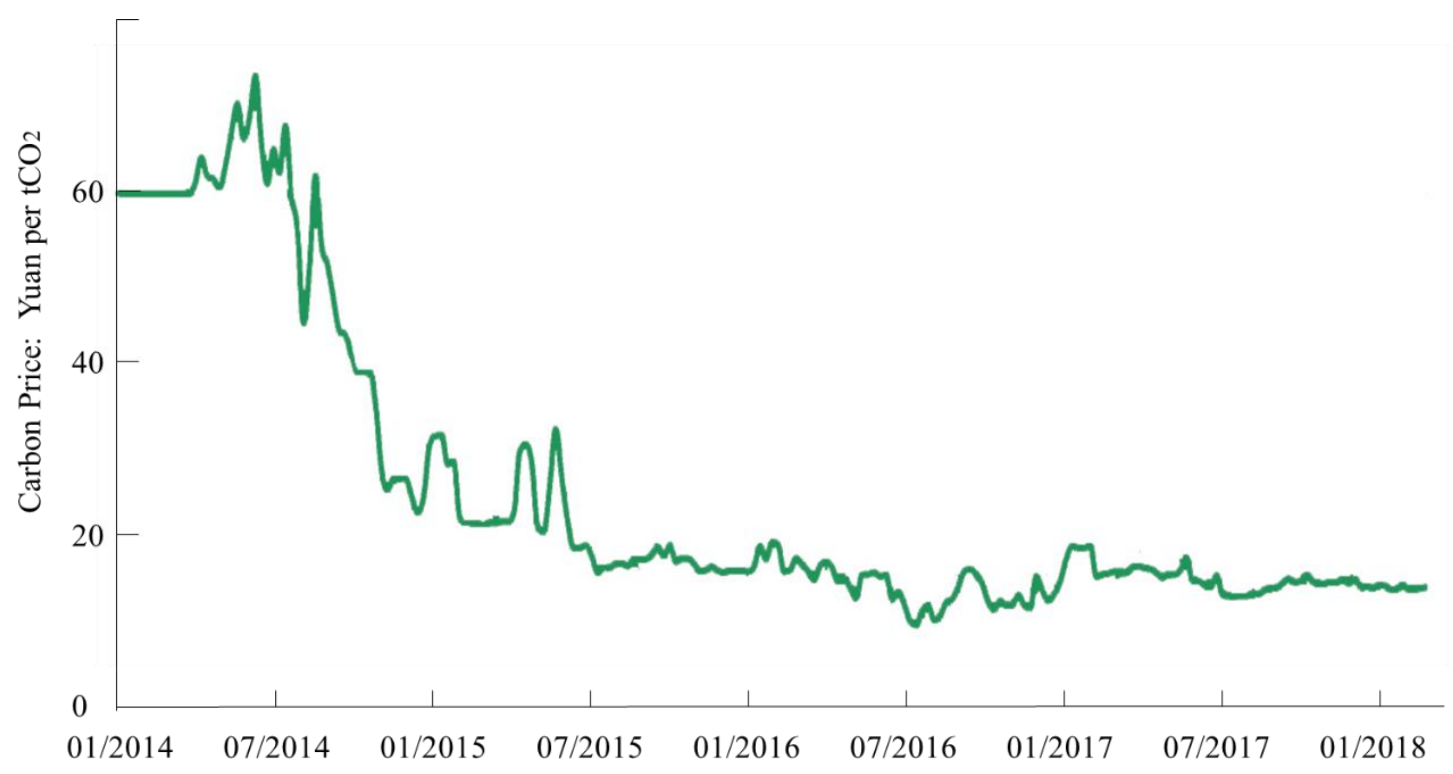

Fig. 2. Carbon K-line of Guangdong pilot ETS

From the individual perspective, each participant with high GDP wants to expand its carbon assets due to the contribution to the economy. Because the promotion of economic growth is the first priority for China, a reasonable allocation method should be built on economic activity principle (Zhou and Wang, 2016). To reflect the negotiation process among diverse participants, this paper adopts the Nash bargaining model (Harsanyi and Selten, 1972; Nash, 1950) and selects GDP as a weight indicator. The reason is that the Nash bargaining model is a non-coalition cooperation game which can reflect the fairness of the negotiation process. Simultaneously, it can ensure each participant's profit to become better after negotiation (Jiang et al., 2017), so that each participant is willing to join the negotiation. Because $p$ is an exogenous variable and carbon quotas are risk neutral, maximizing the 
increment quotas is equivalent to maximizing the carbon assets. Hence, AM is outlined in Eq. (16), and the solution is shown in Appendix $\boldsymbol{A} .2$.

$$
\begin{array}{ll}
\text { Max } & \prod_{i=1}^{n}\left(Q_{i 2020}-Q_{i 2020}^{l}\right)^{w_{i}} \\
\text { s.t. } & \sum_{i=1}^{n} Q_{i 2020} \leq Q_{2020} \\
& Q_{i 2020}^{l} \leq Q_{i 2020} \leq Q_{i 2020}^{u} \\
& \sum_{i=1}^{n} w_{i}=1 \\
& w_{i}=\frac{G D P_{i 2020}}{\sum_{i=1}^{n} G D P_{i 2020}}
\end{array}
$$

where $w_{i}$ represents the bargaining power (weight) of participant $i$.

\subsection{Quota allocation by BPM}

With the concept of sustainable development, more and more scholars consider a trade-off between environmental and financial indicators (Al-E-Hashem et al., 2013), but it is difficult to judge a scheme by a single goal because various goals are sometimes incongruous and even contradictory (Salehi et al., 2017). For instance, expected costs and carbon emissions are two common factors (Konur et al., 2016; Zhao and Li, 2016), but cutting carbon emissions comes at a cost. So the core is to find a non-inferior solution that balance ecological and economic goals (Sazvar et al., 2014). In terms of China, the total amount of carbon quotas is certain. Therefore, the core issue is how to save abatement costs among various levels, so that both regional government and individual participant are satisfied.

More precisely, minimizing the regional TAC is the chief priority for policymakers. However, it may be opposed by some individual participants, because they need to shoulder some extra emission reduction tasks for other participants with high MAC. On the contrary, 
from the individual perspective, each participant with high GDP expects to obtain more initial quotas because of the contribution to economic growth. Due to the discrepancies among different participants, a reasonable allocation approach in practice cannot merely consider unilateral opinions. To achieve a win-win situation between the regional government and the individual participant, this paper simultaneously takes both regional and individual interests into account, and thus BPM is described in Eq. (17), and the solution is shown in Appendix A.3.

$$
\begin{array}{cc}
\operatorname{Min} \sum_{i=1}^{n} T A C_{i 2020} \\
\operatorname{Max} \quad \prod_{i=1}^{n}\left(Q_{i 2020}-Q_{i 2020}^{l}\right)^{w_{i}} \\
\text { s.t. } \quad \sum_{i=1}^{n} Q_{i 2020} \leq Q_{2020} \\
\sum_{i=1}^{n} w_{i}=1 \\
Q_{i 2020}^{l} \leq Q_{i 2020} \leq Q_{i 2020}^{u}
\end{array}
$$

\section{Case study}

\subsection{Overview of the case study}

The PRD region, as the economic, political and cultural center of Guangdong Province, belongs to one of the five major urban agglomerations in China (see Fig.3), accounting for 5\% and $12 \%$ of the national population and GDP, respectively (NBSC, 2017). Although the PRD region has a large amount of economy, the distribution of GDP and population within the region is extremely imbalanced. Most of the contributions come from Guangzhou, Shenzhen, Foshan and Dongguan, while the GDP and population of the remaining cities only account for $20 \%$ and $31 \%$, respectively (see Fig.4).

Moreover, due to the rapid economic development, energy consumption of the PRD region has increased significantly. The energy consumption in 2005 is 140.39 million tons of standard 
coal while this figure reaches 263.97 million tons of standard coal in 2016 (BSGP, 2017). Similar to China, coal is still the primary energy source for the PRD region although the proportion of renewable energy is increasing every year. Because the exploitation and utilization of fossil fuels have caused environmental pollution and ecological destruction, it is dramatically necessary for the PRD region to draft a reasonable emission reduction strategy.

The motivations for selecting the PRD region are shown as follows: (1) the internal development of the PRD region is imbalanced, and thus the allocation of initial carbon quotas should take both individual and regional interests into account; (2) the PRD region covers two pilot ETSs (see Fig. 3), so a special case study not only improves the ETS's performance in the PRD region but also provides references for other ETSs; (3) this study will contribute to the coordinated development of the energy-environment-economy system in the PRD region, so as to realize the adjustment of industrial and energy structure.

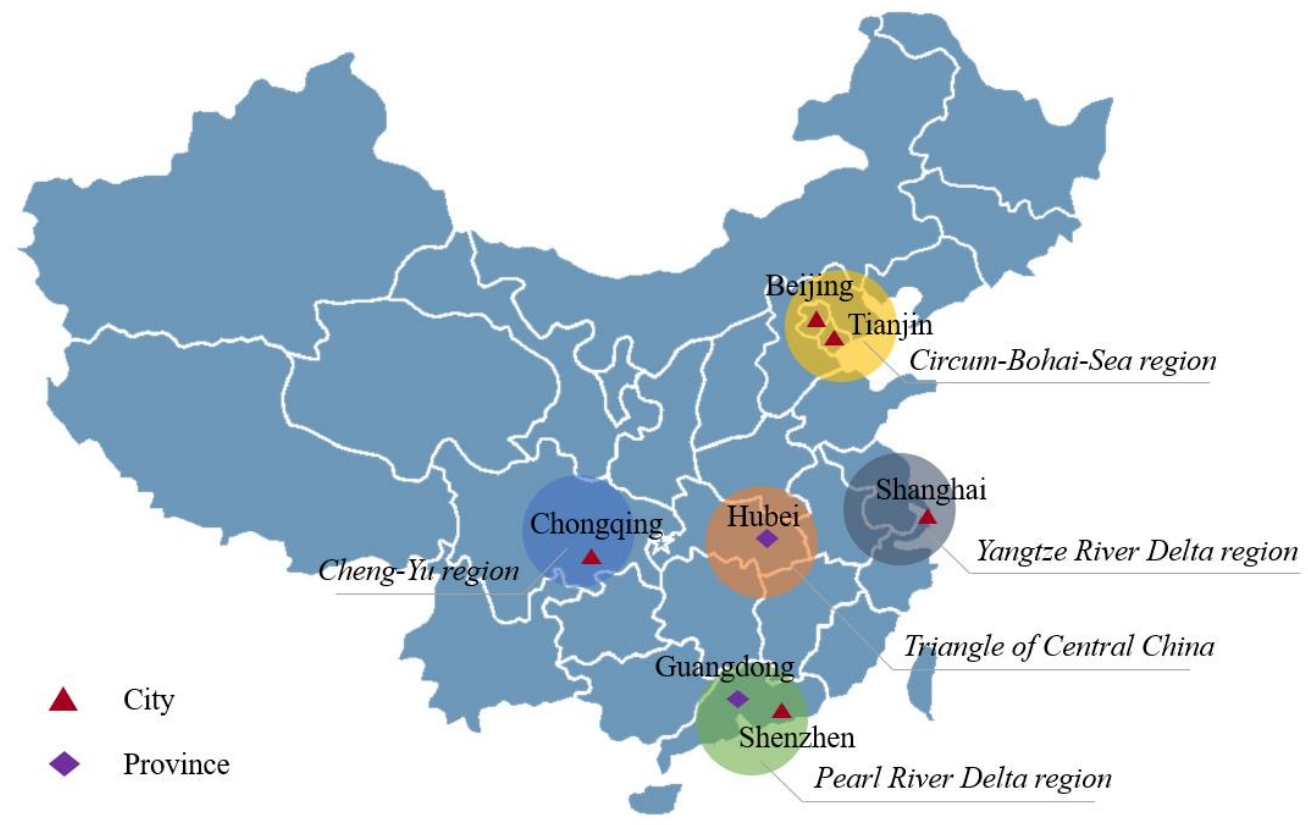

Fig. 3. Five major urban agglomerations and seven pilot ETSs of China 


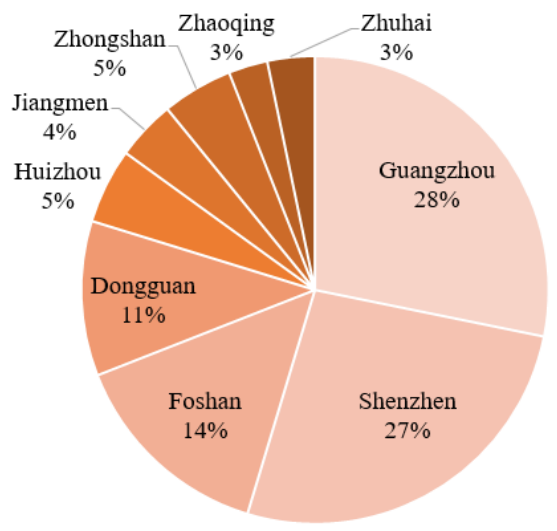

a) GDP

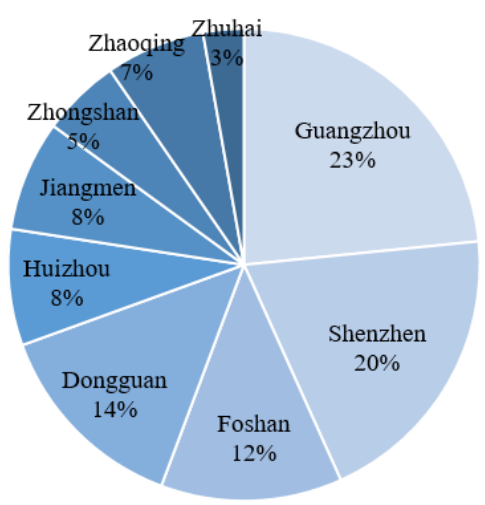

b) Population

Fig. 4. GDP and population of the PRD region in 2016

\subsection{Data collection}

Urban GDP data during the period of 2005-2016 are sourced from Guangdong Statistical Yearbook, and the historical GDP of each city has been measured at the constant price of 2005. Combining Eq. (3) and GDP growth rate (see Table 1) together, this paper estimates the GDP of each city in 2020 through the scenario analysis method. Moreover, according to the 13 th Five-Year Plan (2016-2020) announced by the Chinese government, Guangdong province is required to reduce its carbon emissions per unit of GDP by $20.5 \%$ of the 2015 level by 2020 (CSC, 2016), namely, the $\mu$ in Eq. (5) is equal to $20.5 \%$.

Table 1 The GDP growth rate during the 13th Five-Year Plan

\begin{tabular}{cccc}
\hline \multirow{2}{*}{ Number } & City & $\begin{array}{c}\text { GDP in 2016 } \\
(100 \text { million Yuan })\end{array}$ & $\begin{array}{c}\text { Annual growth rate } \\
(\%)\end{array}$ \\
\hline 1 & Guangzhou & 16980.17 & 7.5 \\
2 & Shenzhen & 15956.74 & 8.2 \\
3 & Foshan & 8663.03 & 7.5 \\
4 & Dongguan & 6451.73 & 8 \\
5 & Huizhou & 3137.38 & 9.5 \\
6 & Zhongshan & 2953.88 & 8.5 \\
7 & Jiangmen & 2487.14 & 9 \\
8 & Zhaoqing & 1633.81 & 9 \\
\hline
\end{tabular}




\begin{tabular}{cccc}
\hline Number & City & $\begin{array}{c}\text { GDP in 2016 } \\
(100 \text { million Yuan })\end{array}$ & $\begin{array}{c}\text { Annual growth rate } \\
(\%)\end{array}$ \\
\hline 9 & Zhuhai & 1978.76 & 9 \\
\hline
\end{tabular}

Data source: The author summarized based on each municipal government's 13th Five-Year Plan.

Note: GDP is calculated at the 2005 constant price index.

Different from other air pollutions, the Chinese government does not publish $\mathrm{CO}_{2}$ data directly. Nevertheless, most studies estimate the carbon emissions through the coefficient method $\left(Q_{i}=\sum_{j=1}^{n} f_{j} \times E C_{i j}\right)$, namely, energy consumption is multiplied by the respective carbon emission coefficient. Because most previous studies are based on the provincial level, various energy consumption data can be obtained from the provincial statistical yearbooks. However, this paper is a research at the city level. Due to the different statistical standards of urban yearbooks, some cities (e.g., Foshan, Dongguan) only count the total energy consumption of industries above the scale, and do not disclose the total energy consumption of the city and various energy consumption data. Although some scholars use GDP or population ratios to estimate energy consumption in cities, such estimates are also inaccurate. Based on the above reasons, this paper adopts the comprehensive factor method (Liao et al., 2015) instead of the traditional coefficient method to estimate the carbon emissions, as shown in Eq. (18).

$$
Q_{i t}=f \times E C_{i t}, i=1,2,3, \ldots, 9
$$

where $Q_{i t}$ and $E C_{i t}$ represent the carbon emissions ( $10^{4}$ tons) and total energy consumption ( $10^{4}$ tons of standard coal) of city $i$ in year $t$, respectively. $f$ is the coefficient for conversion of standard coal to $\mathrm{CO}_{2}$. Based on the announcement of Energy Institute of China National Development and Reform Committee, the carbon content of one ton of standard coal is 0.67 , namely 2.457 tons of $\mathrm{CO}_{2}(1 \times 0.67 \times 44 / 12=2.457$, Liao et al., 2015). Besides, according to the development plan of China's ETS, the main participants in the ETS are 
enterprises and other economic organizations that have annual emissions of 26,000 tons of $\mathrm{CO}_{2}$ equivalent or total energy consumption of 10,000 tons of standard coal (CCTN, 2017). This coefficient (i.e., 2.6) is very close to Liao et al (2015)'s. Because the value of comprehensive factor does not influence the final conclusions (i.e., comparison of three allocation approaches), it only proportionally affects the relative value of the estimates. Therefore, similar to Liao et al (2015), in this paper, $f$ is assumed to be 2.457 .

Finally, because Guangdong Statistical Yearbook does not directly announce the total energy consumption data of each city, this paper calculates the total energy consumption of each city based on energy intensity data (energy consumption per unit of GDP) and its growth rate. The year 2005 is chosen as the base year, which is consistent with the statistical caliber of GDPs. Hence, the carbon intensity of each city and the regional total quotas in 2020 can be calculated based on Eqs. (1) to (5) and (18).

\section{Empirical results and discussions}

\subsection{Allocation results of CM}

Table 2 shows the simulation results of nine cities in the PRD region. All predictions of GM $(1,1)$ that are regarded as the upper bound have achieved high accuracy because all MAPEs are ranging from $[1.79 \%, 4.03 \%]$ and less than $10 \%$. Therefore, these predictions can be used for the subsequent analysis. In addition, Table 2 intuitively reflects that the larger the GDPs, the greater the carbon emissions.

Table 2 Simulation result of the nine cities on the baseline scenario

\begin{tabular}{cccc}
\hline Cities & $\begin{array}{c}\text { GDP in 2020 } \\
(100 \text { million Yuan })\end{array}$ & $\begin{array}{c}Q_{i 2020}^{u} \\
(10 \text { thousand tons })\end{array}$ & $\begin{array}{c}M A P E_{i} \\
(\%)\end{array}$ \\
\hline Guangzhou & 22676.49 & 21118.78 & 2.19 \\
\hline
\end{tabular}




\begin{tabular}{cccc}
\hline Cities & $\begin{array}{c}\text { GDP in 2020 } \\
(100 \text { million Yuan })\end{array}$ & $\begin{array}{c}Q_{i 2020}^{u} \\
(10 \text { thousand tons })\end{array}$ & $\begin{array}{c}M A P E_{i} \\
(\%)\end{array}$ \\
\hline Shenzhen & 21870.23 & 18756.68 & 2.23 \\
Foshan & 11569.21 & 11001.89 & 2.08 \\
Dongguan & 8777.50 & 8582.44 & 2.79 \\
Huizhou & 4510.49 & 7051.21 & 3.67 \\
Zhongshan & 4093.66 & 4185.45 & 1.79 \\
Jiangmen & 3510.80 & 3477.12 & 2.24 \\
Zhaoqing & 2306.25 & 2831.32 & 4.03 \\
Zhuhai & 2793.18 & 2379.06 & 1.94 \\
\hline Total & $\mathbf{8 2 1 0 7 . 8 2}$ & $\mathbf{7 9 3 8 3 . 9 6}$ & $/$ \\
\hline
\end{tabular}

Fig. 5 presents the trends of GDP, carbon emissions and carbon intensity of the PRD region from 2005 to 2020. Firstly, the regional GDP and carbon emissions from 2005 to 2020 both show a rising trend, but GDP growth rate is faster than the carbon emissions growth rate. Therefore, the carbon intensity of the PRD region from 2005 to 2020 decreases gradually. Secondly, the carbon intensity of the PRD region in 2020 is 0.97 ton per ten thousand Yuan, which is higher than the emission reduction target ( 0.9 ton per ten thousand Yuan) required by the state. Similarly, Table 2 also reflects that the total carbon emissions of the PRD region without policy constraint (79383.96 ten thousand tons) is much higher than the policy constraint value $\left(Q_{2020}=73741.60\right.$ ten thousand tons $)$. Therefore, an efficient and feasible emission reduction strategy should be taken in the PRD region instead of simply relying on the natural decreasing of carbon intensity. 


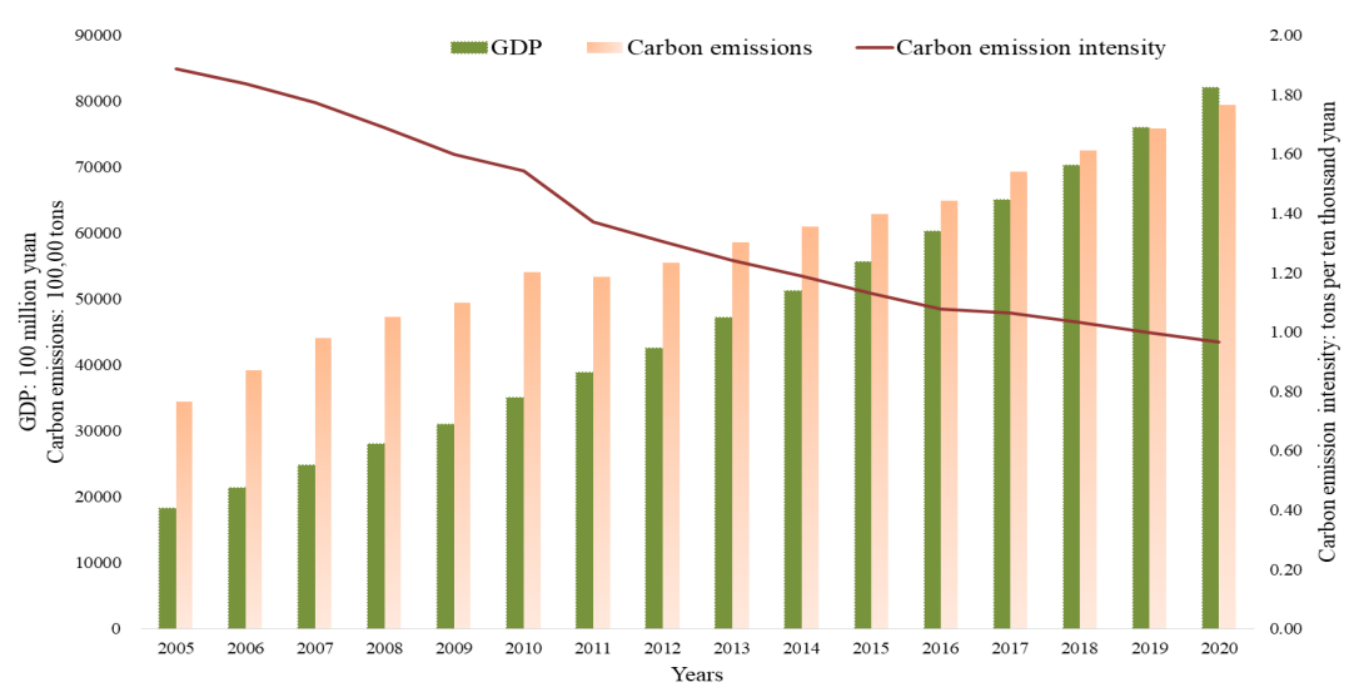

Fig. 5. The trends of GDP, carbon emissions and carbon intensity

Table 3 reveals the allocation results, abatement costs and carbon assets of CM. It can be seen that the initial quotas of Guangzhou and Shenzhen are much larger than other cities because they are more developed than other cities. Although Guangzhou and Shenzhen are assigned more initial quotas, both of them undertake more emission reductions, accounting for $24.94 \%$ and $20.40 \%$ of the total emission reduction tasks, respectively. Nevertheless, these emission reduction tasks will not have a significant impact on these two cities, because the proportions of TAC to carbon assets of Guangzhou and Shenzhen are 1.46 and 1.09, respectively. However, the figures of Zhongshan and Zhuhai are 2.44 and 2.24, respectively, indicating that emission reduction tasks have the greatest impact on these two cities. Moreover, because the goal of CM is tantamount to minimize the TAC of the PRD region, each city has the same MAC which should be equal to the equilibrium carbon trading price (Fan et al., 2016). However, the current carbon trading price in the last three years (see Fig. 2) is far below the equilibrium carbon price (61.42 Yuan per tCO2). Under these circumstances, each city will be a priority for its own interests, and the optimization of $\mathrm{CM}$ will not occur in the real world. Therefore, $\mathrm{CM}$ is only a theoretical optimal allocation approach. 
Table 3 Allocation results of CM

\begin{tabular}{cccccccc}
\hline & \multirow{2}{*}{$Q_{i 2020}$} & \multicolumn{3}{c}{ Abatement costs } & \multicolumn{2}{c}{ Carbon assets } & $T A C_{i 2020}$ \\
\cline { 3 - 7 } Cities & $(10,000$ & & & & \\
& tons) & $A_{i 2020}$ & $M A C_{i 2020}$ & $T A C_{i 2020}$ & $I_{i 2020}$ & $V_{i 2020}$ & $/ V_{i 2020}$ \\
& & $(10,000$ tons $)$ & (Yuan per ton) $)$ & $(10,000$ Yuan $)$ & $(10,000$ tons $)$ & $(10,000$ Yuan $)$ \\
\hline Guangzhou & 19711.50 & 1407.28 & 61.42 & 42240.72 & 1448.50 & 28970.10 & 1.46 \\
Shenzhen & 17605.67 & 1151.01 & 61.42 & 34548.38 & 1586.48 & 31729.51 & 1.09 \\
Foshan & 10253.29 & 748.60 & 61.42 & 22469.88 & 707.27 & 14145.44 & 1.59 \\
Dongguan & 7982.00 & 600.44 & 61.42 & 18022.71 & 776.66 & 15533.27 & 1.16 \\
Huizhou & 6262.49 & 788.72 & 61.42 & 23674.05 & 1223.80 & 24476.03 & 0.97 \\
Zhongshan & 3879.26 & 306.19 & 61.42 & 9190.56 & 188.65 & 3773.03 & 2.44 \\
Jiangmen & 3230.71 & 246.41 & 61.42 & 7396.06 & 291.14 & 5822.79 & 1.27 \\
Zhaoqing & 2582.61 & 248.71 & 61.42 & 7465.16 & 386.55 & 7731.08 & 0.97 \\
Zhuhai & 2234.07 & 144.99 & 61.42 & 4351.91 & 97.12 & 1942.32 & 2.24 \\
\hline Total & $\mathbf{7 3 7 4 1 . 6 0}$ & $\mathbf{5 6 4 2 . 3 5}$ & $/$ & $\mathbf{1 6 9 3 5 9 . 4 2}$ & $\mathbf{6 7 0 6 . 1 8}$ & $\mathbf{1 3 4 1 2 3 . 5 7}$ & $\mathbf{1 . 2 6}$ \\
\hline
\end{tabular}

\subsection{Allocation results of $A M$}

Due to the large volatility of the time series, unit root test is an essential step in time series analysis. If all test series have the same difference and cointegration relationship, Ordinary Least Square (OLS) method can be directly used to determine the model parameters (Li et al., 2017). Therefore, this section first discusses the fittness of EKC. Appendix Table B.1 shows that all test series have passed the Augmented Dickey-Fuller (ADF) test, and Appendix Table B. 2 proves that all EKCs have passed the Johansen Cointegration Test at the 0.05 level except Zhuhai at the 0.1 level. Therefore, it is feasible to estimate the EKC of various cities by the OLS method. According to Eqs. (13), (14) and Table 1, Table 4 displays the simulation results of each city's EKC curve, the lower bound and the peak year.

Table 4 Simulation results of EKC curves

\begin{tabular}{ccccc}
\hline Cities & EKC & $R$ & $Q_{i 2020}^{l}$ & Peak year \\
Guangzhou & $y=-0.1698 x^{2}+3.5602 x-8.814$ & 0.9790 & 18262.99 & 2026 \\
\hline
\end{tabular}




\begin{tabular}{ccccc}
\hline Cities & EKC & $\begin{array}{c}R \\
\text { Square }\end{array}$ & $\begin{array}{c}Q_{\text {i2020 }}^{l} \\
(10 \text { thousand tons })\end{array}$ & Peak year \\
\hline Shenzhen & $y=-0.221 x^{2}+4.6231 x-14.448$ & 0.9963 & 16019.20 & 2026 \\
Foshan & $y=-0.1852 x^{2}+3.4916 x-7.2921$ & 0.9640 & 9546.02 & 2021 \\
Dongguan & $y=-0.3683 x^{2}+6.4972 x-19.747$ & 0.9931 & 7205.33 & 2017 \\
Huizhou & $y=-0.3822 x^{2}+6.3708 x-18.021$ & 0.9869 & 5038.69 & 2019 \\
Zhongshan & $y=-0.119 x^{2}+2.3035 x-2.7132$ & 0.9936 & 3690.61 & 2037 \\
Jiangmen & $y=-0.2657 x^{2}+4.2899 x-9.3276$ & 0.9824 & 2939.57 & 2019 \\
Zhaoqing & $y=-0.2803 x^{2}+4.3333 x-9.0532$ & 0.9805 & 2196.06 & 2020 \\
Zhuhai & $y=-0.1618 x^{2}+2.8067 x-4.4164$ & 0.9842 & 2136.96 & 2029 \\
\hline
\end{tabular}

From Table 4, it can be seen that all EKC curves can well reflect the relationship between carbon emissions and GDP because the Goodness of Fit $\left(R^{2}\right)$ of all curves has exceeded 0.96. In addition, the order of the lower bound is the same as the order of upper bound. It indicates that even if a large volume of initial quotas are given to those small and medium-sized cities (e.g., Zhaoqing and Zhuhai), their GDPs will not grow indefinitely because of other constraints. It is worth noting that Zhongshan might reach its carbon emission peak in 2037, while other cities can reach the peak before 2030. Therefore, Zhongshan must strengthen its low-carbon technological innovation in order to reach the peak in advance.

Table 5 Allocation results of AM

\begin{tabular}{|c|c|c|c|c|c|c|c|}
\hline \multirow{2}{*}{ Cities } & \multirow{2}{*}{$\begin{array}{c}Q_{i 2020} \\
(10,000 \\
\text { tons })\end{array}$} & \multicolumn{3}{|c|}{ Abatement costs } & \multicolumn{2}{|c|}{ Carbon assets } & \multirow{2}{*}{$\begin{array}{l}T A C_{i 2020} \\
/ V_{i 2020}\end{array}$} \\
\hline & & $\begin{array}{c}A_{i 2020} \\
(10,000 \text { tons })\end{array}$ & $\begin{array}{c}M A C_{i 2020} \\
\text { (Yuan per ton) }\end{array}$ & $\begin{array}{c}T A C_{i 2020} \\
(10,000 \text { Yuan })\end{array}$ & $\begin{array}{c}I_{i 2020} \\
(10,000 \text { tons })\end{array}$ & $\begin{array}{c}V_{i 2020} \\
(10,000 \text { Yuan })\end{array}$ & \\
\hline Guangzhou & 20076.91 & 1041.87 & 44.65 & 22879.50 & 1813.92 & 36278.39 & 0.63 \\
\hline Shenzhen & 17768.76 & 987.92 & 52.19 & 25286.66 & 1749.56 & 34991.24 & 0.72 \\
\hline Foshan & 10471.37 & 530.52 & 42.65 & 11136.23 & 925.35 & 18507.05 & 0.6 \\
\hline Dongguan & 7907.39 & 675.05 & 69.67 & 22912 & 702.05 & 14041.04 & 1.63 \\
\hline
\end{tabular}




\begin{tabular}{cccccccc} 
Huizhou & 5399.24 & 1651.97 & 139.82 & 109556.5 & 360.55 & 7211.06 & 15.19 \\
Zhongshan & 4156.42 & 29.03 & 5.48 & 79.34 & 465.82 & 9316.33 & 0.01 \\
Jiangmen & 3220.66 & 256.46 & 64.11 & 8027.36 & 281.08 & 5621.63 & 1.43 \\
Zhaoqing & 2380.6 & 450.72 & 118.26 & 25493.71 & 184.55 & 3690.93 & 6.91 \\
Zhuhai & 2360.25 & 18.81 & 7.51 & 70.46 & 223.30 & 4465.91 & 0.02 \\
\hline Total & $\mathbf{7 3 7 4 1 . 6}$ & $\mathbf{5 6 4 2 . 3 5}$ & / & $\mathbf{2 2 5 4 4 1 . 8}$ & $\mathbf{6 7 0 6 . 1 8}$ & $\mathbf{1 3 4 1 2 3 . 6}$ & $\mathbf{1 . 6 8}$ \\
\hline
\end{tabular}

Table 5 shows the results of AM. It can be seen that Guangzhou and Shenzhen still have the largest initial quotas due to higher bargaining power (i.e., economic level). Besides, the increment quotas of Guangzhou and Shenzhen are much higher than other cities, indicating that the TACs of these two cities will have less impact on their economic growth. Furthermore, besides Huizhou, Jiangmen, Zhaoqing and Dongguan, the MACs of other cities are lower than the equilibrium carbon price, indicating that they are more likely to profit from ETS. On the contrary, the MACs of Huizhou and Zhaoqing are 139.82 and 118.26 Yuan per ton respectively, which are much higher than other cities. To this end, the proportions of TAC to carbon assets of Huizhou and Zhaoqing are 15.19 and 6.91, respectively, but the figures of Zhongshan and Zhuhai are close to zero, reflecting the unfair share of TAC. All the above results indicate that $\mathrm{AM}$ is to promote the development of other cities by sacrificing the development of Huizhou and Zhaoqing, which is not conducive to the coordinated development of the PRD region.

\subsection{Allocation results of BPM}

The allocation results using BPM are shown in Table 6. On the one hand, similar to CM and AM, although Guangzhou and Shenzhen still have the largest initial quotas, they also need to undertake the largest reduction tasks, accounting for $31.46 \%$ and $25.98 \%$ of the total tasks, respectively. Moreover, the MACs of Guangzhou and Shenzhen are slightly higher than the equilibrium carbon price, and the TACs of Guangzhou and Shenzhen in BPM are 68016.95 and 
56741.00 ten thousand Yuan, respectively. To this end, the proportions of TAC to carbon assets of Guangzhou and Shenzhen are 3.15 and 2.23, respectively. Although Guangzhou and Shenzhen assume more responsibility, it has little impact on their economic development because of the high economic level. Actually, Guangzhou and Shenzhen, the most developed cities in the PRD region, have released most of the $\mathrm{CO}_{2}$ in history. Therefore, shouldering more emission reduction tasks is the embodiment of "polluter pay principle" (Fan et al., 2016).

Table 6 Allocation results of BPM

\begin{tabular}{|c|c|c|c|c|c|c|c|}
\hline \multirow{2}{*}{ Cities } & \multirow{2}{*}{$\begin{array}{c}Q_{i 2020} \\
(10,000 \\
\text { tons })\end{array}$} & \multicolumn{3}{|c|}{ Abatement costs } & \multicolumn{2}{|c|}{ Carbon assets } & \multirow{2}{*}{$\begin{array}{l}T A C_{i 2020} \\
/ V_{i 2020}\end{array}$} \\
\hline & & $\begin{array}{c}A_{i 2020} \\
(10,000 \text { tons })\end{array}$ & $\begin{array}{c}M A C_{i 2020} \\
\text { (Yuan per ton) }\end{array}$ & $\begin{array}{c}T A C_{i 2020} \\
(10,000 \text { Yuan })\end{array}$ & $\begin{array}{c}I_{i 2020} \\
(10,000 \text { tons })\end{array}$ & $\begin{array}{c}V_{i 2020} \\
(10,000 \text { Yuan })\end{array}$ & \\
\hline Guangzhou & 19343.89 & 1774.89 & 78.93 & 68016.95 & 1080.9 & 21618.06 & 3.15 \\
\hline Shenzhen & 17291.02 & 1465.66 & 79.77 & 56741.00 & 1271.82 & 25436.45 & 2.23 \\
\hline Foshan & 10492.59 & 509.30 & 40.87 & 10250.22 & 946.57 & 18931.40 & 0.54 \\
\hline Dongguan & 8298.52 & 283.92 & 28.01 & 3934.89 & 1093.19 & 21863.79 & 0.18 \\
\hline Huizhou & 6344.74 & 706.47 & 54.61 & 18903.06 & 1306.05 & 26121.03 & 0.72 \\
\hline Zhongshan & 3887.96 & 297.49 & 59.55 & 8664.43 & 197.35 & 3947.00 & 2.20 \\
\hline Jiangmen & 3238.47 & 238.65 & 59.35 & 6927.78 & 298.89 & 5977.89 & 1.16 \\
\hline Zhaoqing & 2590.26 & 241.06 & 59.40 & 7003.20 & 394.20 & 7884.02 & 0.89 \\
\hline Zhuhai & 2254.15 & 124.91 & 52.40 & 3209.43 & 117.20 & 2343.93 & 1.37 \\
\hline Total & 73741.60 & 5642.35 & / & 183651 & 6706.18 & 134123.6 & 1.37 \\
\hline
\end{tabular}

On the other hand, BPM can help to promote the development of small and medium-sized cities, so as to achieve the coordinated development of the PRD region. First, the MACs of the remaining cities are lower than the equilibrium carbon price, indicating that the small and medium-sized cities have more potential to take advantage of the initial quotas. Moreover, the regional TAC in BPM is 183650.97 ten thousand Yuan, which is 14291.54 ten thousand Yuan higher than the TAC in CM. Nevertheless, all of the extra abatement costs are borne by Guangzhou and Shenzhen. Therefore, small and medium-sized cities can obtain more emission space to promote their economic development. 


\subsection{Comparison of different allocation results}

According to the above analysis, it can be seen that $\mathrm{CM}$ has the lowest regional TAC (169359.42 ten thousand Yuan), while the regional TACs of AM and BPM are 225441.8 and 183651 ten thousand Yuan, respectively. Therefore, from the PRD region's perspective, CM is the best allocation approach, and BPM can be regarded as a sub-optimal solution, although it requires an additional payment of 142.9154 million Yuan.

Table 7 Comparisons of different allocation models

\begin{tabular}{ccccccc}
\hline \multirow{2}{*}{ Cities } & \multicolumn{2}{c}{ CM } & \multicolumn{2}{c}{ AM } & \multicolumn{2}{c}{ BPM } \\
\cline { 2 - 7 } & $Q_{i 2020}$ & Proportions & $Q_{i 2020}$ & Proportions & $Q_{i 2020}$ & Proportions \\
\hline Guangzhou & 19711.50 & $26.73 \%$ & 20076.91 & $27.23 \%$ & 19343.89 & $26.23 \%$ \\
Shenzhen & 17605.67 & $23.87 \%$ & 17768.76 & $24.10 \%$ & 17291.02 & $23.45 \%$ \\
Foshan & 10253.29 & $13.90 \%$ & 10471.37 & $14.20 \%$ & 10492.59 & $14.23 \%$ \\
Dongguan & 7982.00 & $10.82 \%$ & 7907.39 & $10.72 \%$ & 8298.52 & $11.25 \%$ \\
Huizhou & 6262.49 & $8.49 \%$ & 5399.24 & $7.32 \%$ & 6344.74 & $8.60 \%$ \\
Zhongshan & 3879.26 & $5.26 \%$ & 4156.42 & $5.64 \%$ & 3887.96 & $5.27 \%$ \\
Jiangmen & 3230.71 & $4.38 \%$ & 3220.66 & $4.37 \%$ & 3238.47 & $4.39 \%$ \\
Zhaoqing & 2582.61 & $3.50 \%$ & 2380.60 & $3.23 \%$ & 2590.26 & $3.51 \%$ \\
Zhuhai & 2234.07 & $3.03 \%$ & 2360.25 & $3.20 \%$ & 2254.15 & $3.06 \%$ \\
\hline Total & $\mathbf{7 3 7 4 1 . 6 0}$ & $\mathbf{1 0 0 \%}$ & $\mathbf{7 3 7 4 1 . 6 0}$ & $\mathbf{1 0 0 \%}$ & $\mathbf{7 3 7 4 1 . 6 0}$ & $\mathbf{1 0 0 \%}$ \\
\hline
\end{tabular}

Because the total initial quotas of the PRD region in 2020 are fixed, namely 73741.60 ten thousand tons. If a city is assigned more initial quotas, other cities will be allocated less. Consequently, each city will prefer the allocation model that will give it more initial quotas. From the individual perspective, this paper finds some opposite conclusions corresponding to the regional perspective (see Table 7). Guangzhou, Shenzhen, Zhongshan and Zhuhai prefer $\mathrm{AM}$ and the remaining cities prefer BPM. Although CM has the lowest regional TAC, none of the cities prefer it, indicating that if all the cities only consider the maximization of their own interests, it will hinder the realization of low-cost emission reduction in the PRD region. In 
addition, BPM is the sub-optimal allocation approach for Zhongshan and Zhuhai, while it is the worst approach for Guangzhou and Shenzhen.

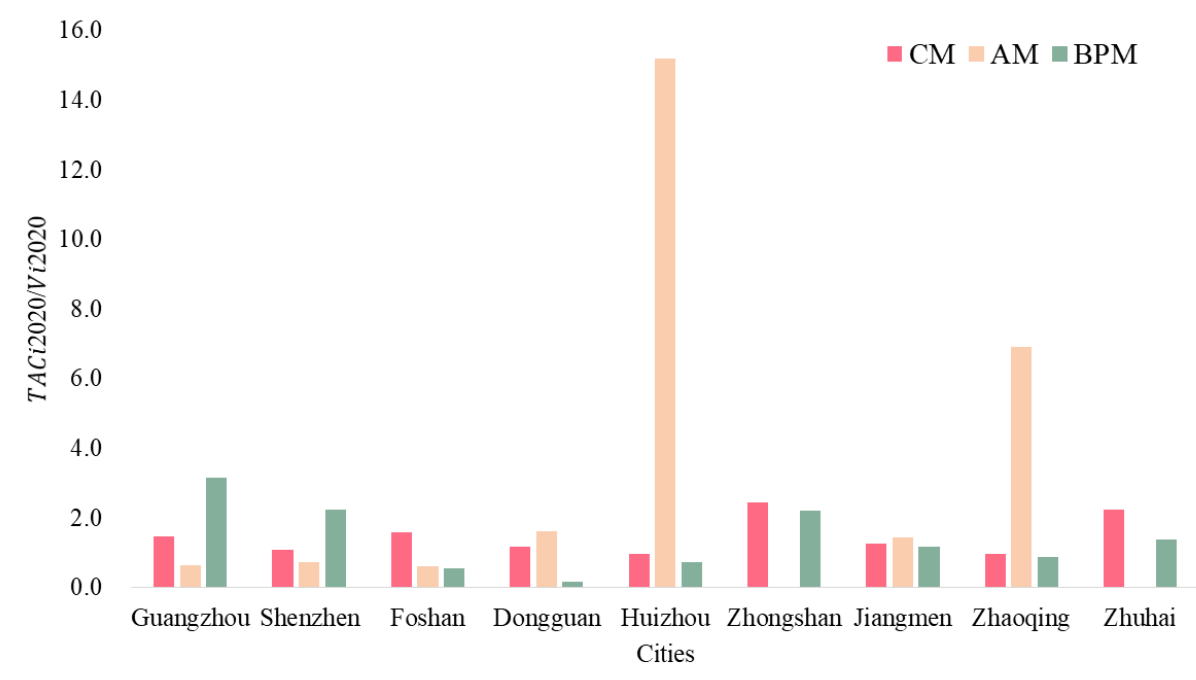

Fig. 6. The ratio of each city's abatement costs to the carbon assets

Fig. 6 shows the ratio of each city's TAC to carbon assets. Obviously, the distribution of AM is extreme. The ratios of Huizhou and Zhaoqing in AM are15.19 and 6.91 respectively, while the ratios of Zhuhai and Zhongshan in AM are close to zero. It indicates that the emission reduction tasks of Huizhou and Zhaoqing have a negative impact on their economic growth, which will hinder the long-term coordinated development of the PRD region. In terms of CM, although the ratios of Zhongshan and Zhuhai are still high, CM can mitigate the extreme distribution of abatement costs, which can reflect the fairness of quota allocation. Compared with AM, BPM is also a feasible model, because Guangzhou and Shenzhen undertake more emission reduction tasks, making the distribution of different cities tend to average.

At present, there are two main measures to reduce $\mathrm{CO}_{2}$ concentration. One is to reduce carbon sources by implementing low-carbon technologies, and the other is to increase carbon sinks (Han et al., 2016). Forest, as a major reservoir in the atmospheric carbon cycle, is the main body of carbon sink function in the terrestrial ecosystem (Peck et al., 2017). Therefore, 
the quota allocation should both take into account the investment cost of low carbon technologies and the number of carbon sinks in each city. Fig. 7 shows the forest coverage rate of different cities in the PRD region (JNU, 2018). The darker the color, the higher the forest coverage rate. Obviously, forest coverage rates of Zhaoqing and Huizhou are much higher than other cities, accounting for $70.30 \%$ and $62.34 \%$ of the total urban area, respectively. It indicates that these two cities have made a great contribution to the absorption of carbon emissions. However, in terms of AM, the initial quotas of Huizhou and Zhaoqing are 5399.24 and 2380.60 ten thousand tons, accounting for $7.32 \%$ and $3.23 \%$ of the total initial quotas, respectively. It has greatly affected the enthusiasm of these two cities to reduce emission. On the contrary, in BPM, these two cities have the lowest TACs, so as to mobilize the emission reduction enthusiasm of these two cities and set an example for other cities.

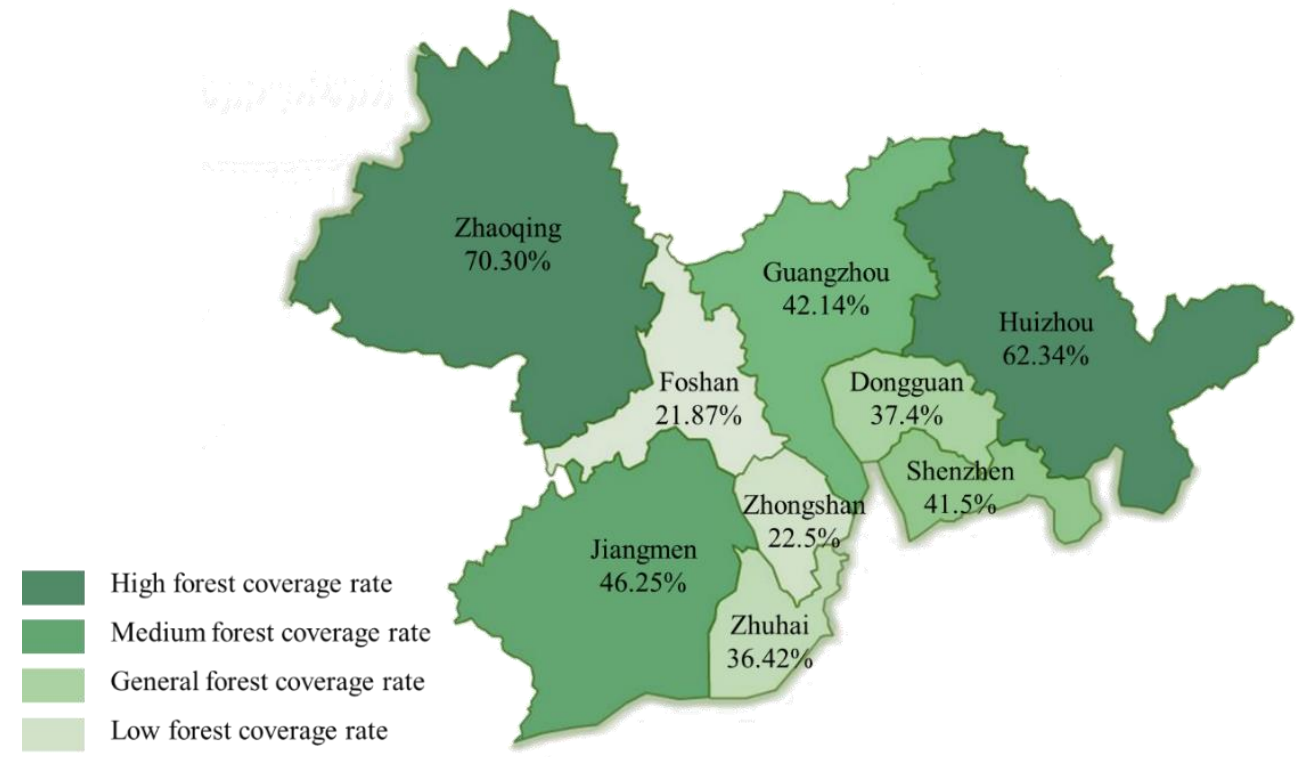

Fig. 7. The forest coverage rate of nine cities in the PRD region

Furthermore, based on the urban Statistical Yearbook, this paper analyses the spatial distribution of various types of pollutants. A principal finding is that $\mathrm{SO}_{2}$ is concentrated in Guangzhou, Dongguan and Foshan, while $\mathrm{CO}_{2}, \mathrm{NO}_{\mathrm{X}}, \mathrm{PM} 10$ and PM 2.5 are mainly distributed 
in Dongguan, Guangzhou, Foshan and Shenzhen. All the mentioned cities have high industrial level, energy consumption, and population density. Based on the "polluter pays principle", a city with higher economic level and historical carbon emissions should shoulder more responsibilities and obligations to reduce emissions (Fan et al., 2016). From Table 3, 5 and 6, it can be seen that the total abatement volume of the above four cities in BPM is 4033.77 ten thousand tons, while those figures in CM and AM are 3907.34 and 3235.37 ten thousand tons, respectively. Therefore, BPM can best reflect the "polluter pays principle", making the allocation results more acceptable to various cities.

\section{Sensitivity analysis}

For the sake of analysis, this paper assumes that the initial quotas for participants are $100 \%$ freely available. However, in the context of China's carbon resource management, the ratio of free quota is from $95 \%$ to $97 \%$ ( $\mathrm{Li}$ and Jia, 2016). Besides, due to the uncertainty of GDP growth and energy consumption, the regional total quotas by 2020 may be less or exceed the policy constraint value assumed (i.e., 73741.60 ten thousand tons). Therefore, in this section, a sensitivity analysis will be carried out on the change of regional total quotas. Remarkably, carbon quotas obtained by each participant must be within its boundaries (i.e., $Q_{i 2020}^{l} \leq$ $Q_{i 2020} \leq Q_{i 2020}^{u}$ ), which is an important prerequisite for this paper. Following this principle, three scenarios are considered, namely, the regional total quotas change by $+4 \%,-4 \%$ and $-8 \%$, respectively. The latter two scenarios can be regarded as $96 \%$ or $92 \%$ of quotas are freely allocated.

To provide a clear explanation from the individual perspective, two important relationships 
are shown as follows: (i) the ranking of absolute emission reductions $\left(Q_{i 2020}^{u}-Q_{i 2020}^{l}\right.$, unit: ten thousand tons) is, Guangzhou (2855.79) > Shenzhen (2737.48) > Huizhou (2012.52) > Foshan $(1455.87)>$ Dongguan $(1377.11)>$ Zhaoqing $(635.26)>$ Jiangmen $(537.55)>$ Zhongshan (494.84) > Zhuhai (242.10); (ii) the ranking of bargaining power $\left(w_{i}\right)$ is, Guangzhou $(0.2762)>$ Shenzhen (0.2664) > Foshan (0.1409) $>$ Dongguan (0.1069) $>$ Huizhou (0.0549) $>$ Zhongshan $(0.0499)>$ Jiangmen $(0.0428)>$ Zhuhai $(0.0340)>$ Zhaoqing $(0.0281)$. From Fig. 8, it can be seen that no matter how the total quotas changes, Guangzhou, Zhongshan and Zhuhai always prefer AM because their economic level is higher than other cities of the same class. For Shenzhen, when the regional total quotas are tightened, it will tend to CM due to relatively large absolute emission reductions and the principle of first meeting the minimum quota for each city. This situation will not occur in Guangzhou, because the lower bound of Guangzhou is 2243.80 ten thousand tons higher than Shenzhen. With the increase of regional total quotas, Shenzhen's economic advantage is gradually reflected, so it will turn to AM. Similar to Shenzhen, Huizhou and Zhaoqing will choose $\mathrm{CM}$ when the regional total quotas are tightened. Separately, with the loosening of regional total quotas, they can only maximize their interests through BPM because of the economic constraints. Remarkably, when regional carbon quotas are particularly abundant (i.e., $+4 \%$ scenario), Huizhou will once again choose CM that is dominated by its emission reduction. Even so, Huizhou's carbon quotas under BPM are only 27.71 ten thousand tons less than that under CM, which is a sub-optimal choice for Huizhou. Finally, with respect to the remaining cities, their choices will vary between AM and BPM, because their characteristics are not prominent. 

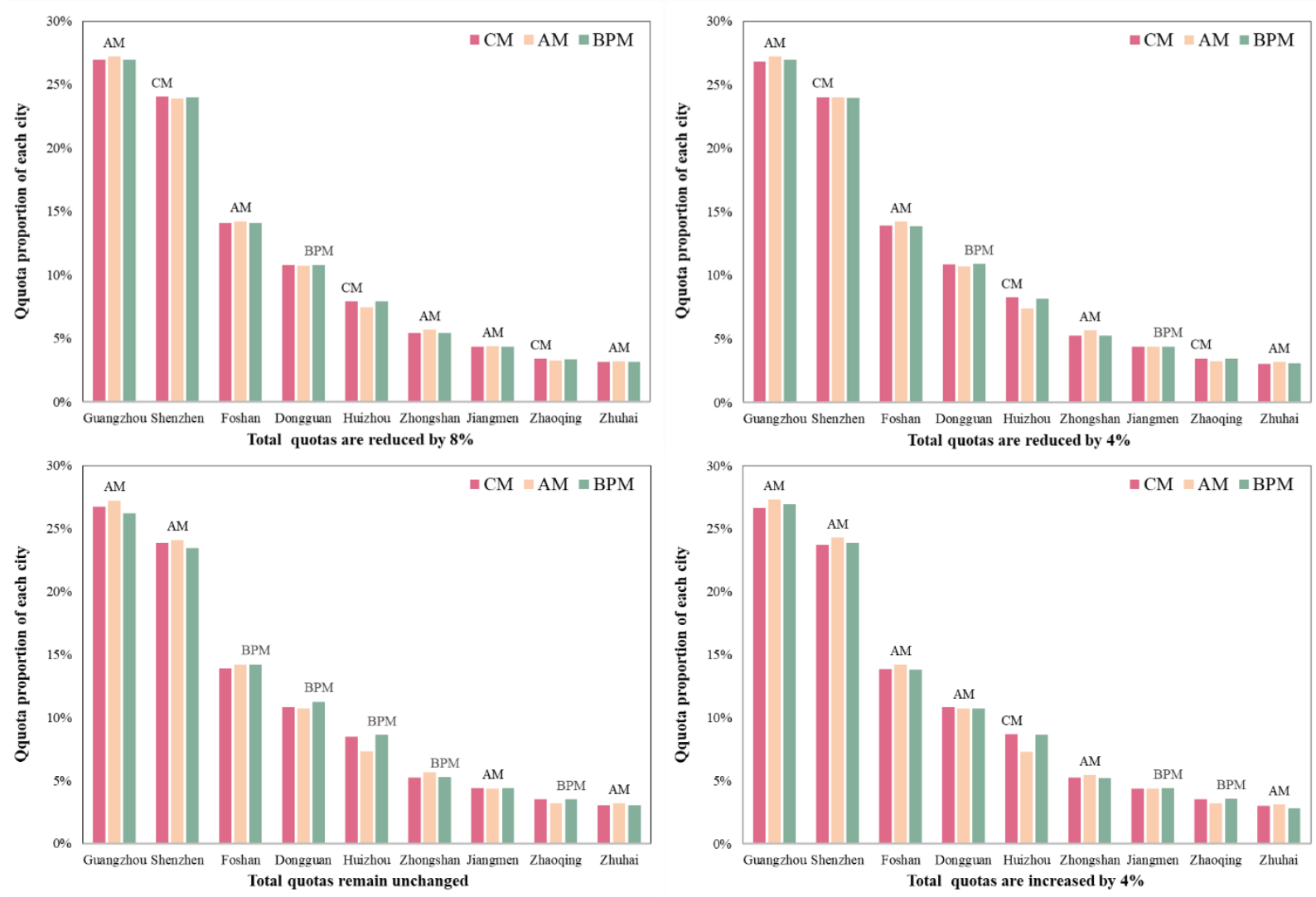

Fig. 8 Changes in individual selection patterns

Fig. 9 reveals the trend of regional TAC as a function of regional total quotas. Undoubtedly, regardless of the allocation method, the regional TAC will decrease as the total quotas increase, and the regional TAC of three approaches can always be ranked as follows: $\mathrm{CM}<\mathrm{BPM}<\mathrm{AM}$. Moreover, with the increase of regional total quotas, the cost gap between different allocation methods is gradually increasing. Specifically, when the regional total quotas are reduced by $8 \%$, the cost gap between AM and BPM (BPM and CM) is 21199.69 (65.19) ten thousand Yuan; however, when the regional total quotas are increased by $4 \%$, the cost gap between AM and BPM (BPM and CM) is increased to 65281.43 (8560.64) ten thousand Yuan. Therefore, from the PRD region's perspective, CM is always the best allocation approach, and BPM is a suboptimal solution. 


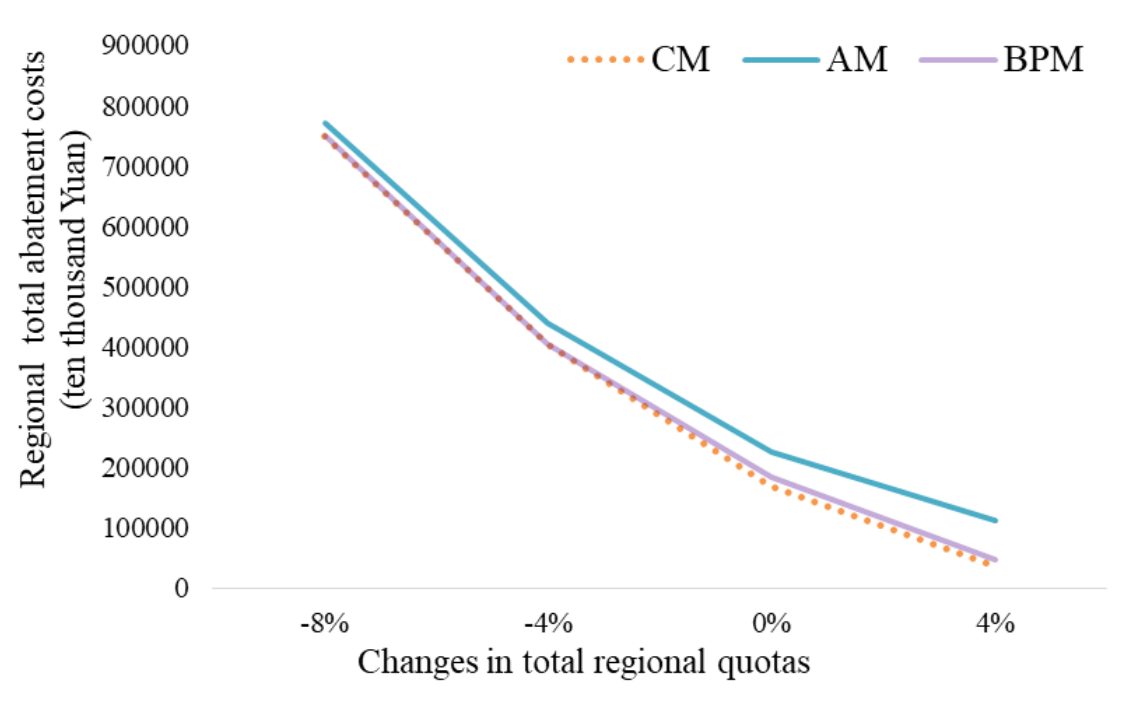

Fig. 9 Changes in regional total abatement costs

In brief, when the regional total quotas are tightened, the advantage of the economic level is not obvious because the emission reduction tasks dominate, reflected in the small regional TAC gap. However, with the increase of regional total quotas, those cities with high economic levels will use their bargaining power to secure more quotas, which lead to the expansion of the cost gap. Undoubtedly, it will widen the gap between developed and developing cities. Fortunately, BPM achieves a trade-off between regional TAC and individual interests. Although the regional TAC has been slightly increased, it provides more development space for cities that contribute more to urban greening (e.g., Huizhou and Zhaoqing). This feature of BPM becomes increasingly apparent as the total quotas increase. Based on the above analysis, BPM is considered to be the most appropriate approach.

\section{Conclusions and Policy implications}

\subsection{Main conclusions}

As a core component of the ETS, the allocation of initial carbon quotas will make a profound impact on the ETS's operation. The existing literature mostly allocates the initial 
quotas from a single perspective. However, carbon emission reduction is a comprehensive process regarding the coordinated development of economy, energy and environment (Chang and Lee, 2016). Simply considering a single goal of emission reduction is not enough in the actual implementation process. On the basis of that, this paper presents a BPM to allocate the initial carbon quotas, which consider a trade-off between overall interests and individual interests. To show the advantages of the proposed model, this paper selects the PRD region as an example and compares the results with $\mathrm{CM}$ and $\mathrm{AM}$. The main findings are shown as follows.

First, simply relying on the natural decreasing of carbon intensity will not achieve the national emission reduction targets. In terms of the PRD region, the carbon intensity in 2020 without policy constraint is 0.97 ton per ten thousand Yuan, whereas the national target is 0.9 ton per ten thousand Yuan. Therefore, an effective and feasible emission reduction strategy is particularly important for the PRD region.

Moreover, the allocation results with different allocation approaches reveal that the regional government will prefer $\mathrm{CM}$, which always has the lowest regional TAC. But it might have some obstacles in actual implementation because each participant is rational and wants to maximize its interests. From the individual perspective, more cities prefer AM while Huizhou and Zhaoqing will refuse it because of high abatement costs and the great contribution of forest coverage rate. There is no doubt that AM runs counter to the coordinate development goal of the PRD region, especially when the regional total quotas are sufficient. Therefore, it is necessary for the PRD region to design an appropriate allocation approach from a multiperspective, which can achieve a trade-off between overall interests and individual interests.

Last but not least, BPM is regarded as an efficient and feasible allocation approach. Firstly, 
it can coordinate the relationship between abatement costs and carbon assets, because the cost gap between BPM and CM is much smaller than the cost gap between AM and BPM. Secondly, it gives more development space to cities with large green contributions, which is an affirmation and recognition of their green contributions. Thirdly, compared with AM, the additional quota increments for small and medium-sized cities are mainly from those developed cities that have high industrial level and energy consumption. Therefore, BPM can better reflect the "polluter pays principle" and narrow the development gaps between different cities.

\subsection{Policy implications}

To better promote emission reduction, this paper provides some useful implications for policymakers in the context of ETS's operation. First, the PRD region should optimize the design of carbon emission quota allocation, because carbon emission space is the space for development. However, current allocation methods mainly focus on a single perspective, which will lead to unfair allocation. Therefore, to ensure the allocation method trailed to the actual circumstance, the policymakers should take into account different objectives (e.g., abatement costs, carbon assets, energy consumption level and social welfare), so as to achieve the coordinated development of environment, energy and economy, and the balance of overall and individual interests.

Moreover, the PRD region should promote energy market reform and ETS legislation, so as to secure the effective operation of the ETS. One of the preconditions for the effective ETS is that all cities have the same MAC that is equal to the equilibrium carbon prices. However, the current carbon trading price of the PRD region is much lower than the equilibrium carbon 
prices. Therefore, policymakers need to strengthen ETS legislation to ensure the stability of the carbon trading price. In addition, policymakers also need to enact specific regulations (e.g., monitoring, reporting and verification) for each aspect of carbon emissions, so that the carbon emission reduction action can be effectively implemented.

Finally, to achieve the emission reduction target, on the one hand, the PRD region needs to reduce carbon emissions at the source. For example, nuclear energy, as a clean energy with high Energy Return on Investment (EROI), should gradually replace coal as the main source of energy supply (Wang et al., 2016). Moreover, electric vehicle technologies (Walmsley et al., 2015) and carbon capture and storage technologies (Zhou et al., 2014) should be vigorously promoted to reduce the carbon emissions from the transport sector and the energy sector, respectively. On the other hand, the PRD region also needs to increase the channel of carbon sinks, such as expanding the urban green area and the forest coverage rate. With the implementation of emission reduction, the emission reduction space in the future will continue to shrink. Therefore, it is necessary for the PRD region to expand the ETS coverage and to incorporate different types of industrial exhaust, such as $\mathrm{SO}_{2}, \mathrm{NO}, \mathrm{PM} 10$ and PM 2.5, so as to achieve a steady decline for atmospheric pollutants.

\subsection{Limitations and future research directions}

Due to the different statistical caliber, this paper estimates the carbon emissions of each city based on the comprehensive factor method and the development plan of China's ETS. More accurate statistics will help expand the contribution of this paper. In addition, the solution of the bi-objective programming model is by using the function of fgoalattain in Matlab R2016a, 
which is based on the goal attainment method. Other calculation principles, such as the linear weighting method, the sum of the square weighting method and the constraint model, can be investigated in the future. Finally, this paper only considers two goals of abatement costs and carbon assets, more reasonable goals (e.g., employment rate, carbon sources, and sinks) can be incorporated into future work.

\section{Acknowledgments}

The authors thank the anonymous reviewers for their constructive comments to improve the quality of this work. This study is supported by National Natural Science Foundation of China [grant numbers 71371006, 71471066, 71771090, 71420107024]; and Science and Technology Program of Guangzhou, China [grant number 201707010362]. 


\section{Appendix A}

\section{A.1 Program of CM}

function $f_{1}=\operatorname{TAC}(x)$

$f_{1}=\sum_{i=1}^{n} 453.15\left[Q_{i 2020}^{u}\left(1-r_{i}\right)-\left(Q_{i 2020}^{u}-x_{i}\right)\right] \ln \left(1-\frac{Q_{i 2020}^{u}-x_{i}}{Q_{i 2020}^{u}\left(1-r_{i}\right)}\right)+453.15\left(Q_{i 2020}^{u}-x_{i}\right)$

$x_{o}=\left[Q_{12020}^{l}, Q_{22020}^{l}, \ldots Q_{i 2020}^{l}\right]^{\prime}$

$l b=x_{o} ; A=\operatorname{ones}(1, n) ; \quad b=\left[Q_{2020}\right] ;$

$u b=\left[Q_{12020}^{u}, Q_{22020}^{u}, \ldots Q_{i 2020}^{u}\right]^{\prime}$

$[x, f v a l]=$ fmincon $\left(@ T A C, x_{o}, A, b,[],[], l b, u b\right)$

\section{A.2 Program of $A M$}

function $f_{2}=\operatorname{asset}(x)$

$$
f_{2}=-\prod_{i=1}^{9}\left(x_{i}-Q_{i 2020}^{l}\right)^{w_{i}}
$$

$x_{o}=\left[Q_{12020}^{l}, Q_{22020}^{l}, \ldots Q_{i 2020}^{l}\right]^{\prime}$

$l b=x_{o} ; \quad A=\operatorname{ones}(1, n) ; \quad b=\left[Q_{2020}\right] ;$

$u b=\left[Q_{12020}^{u}, Q_{22020}^{u}, \ldots Q_{i 2020}^{u}\right]^{\prime}$

$[x, f v a l]=$ fmincon $\left(@ a s s e t, x_{o}, A, b,[],[], l b, u b\right)$

\section{A.3 Program of BPM}

function $f_{3}=B P M(x)$

$$
\begin{aligned}
& f(1)=\sum_{i=1}^{9} 453.15\left[Q_{i 2020}^{u}\left(1-r_{i}\right)-\left(Q_{i 2020}^{u}-x_{i}\right)\right] \ln \left(1-\frac{Q_{i 2020}^{u}-x_{i}}{Q_{i 2020}^{u}\left(1-r_{i}\right)}\right)+453.15\left(Q_{i 2020}^{u}-x_{i}\right) \\
& f(2)=-\prod_{i=1}^{9}\left(x_{i}-Q_{i 2020}^{l}\right)^{w_{i}} \\
& \text { goal }=\left[f_{1}^{*} f_{2}^{*}\right] \\
& \text { weight }=\left[f_{1}^{*} f_{2}^{*}\right] \\
& x_{o}=\left[Q_{12020}^{l}, Q_{22020}^{l}, \ldots Q_{i 2020}^{l}\right]^{\prime}
\end{aligned}
$$




$$
\begin{aligned}
& l b=x_{o} ; A=\operatorname{ones}(1, n) ; \quad b=\left[Q_{2020}\right] ; \\
& u b=\left[Q_{12020}^{u}, Q_{22020}^{u}, \ldots Q_{i 2020}^{u}\right]^{\prime} \\
& {[x, \text { fval }]=\text { fgoalattain }\left(@ B P M, x_{o}, \text { goal, weight }, A, b,[],[], l b, u b\right)}
\end{aligned}
$$

\begin{tabular}{|c|c|c|c|c|c|c|c|}
\hline Cities & Variables & $\begin{array}{c}\text { Difference } \\
\text { times }\end{array}$ & $(C, T, K)$ & $A D F$ & $\begin{array}{c}5 \% \\
\text { level }\end{array}$ & $\begin{array}{c}1 \% \\
\text { level }\end{array}$ & Results \\
\hline \multirow{3}{*}{ Guangzhou } & $\ln Q_{i 2020}$ & $2 \mathrm{nd}$ & $(0,0,1)$ & -3.035 & -1.996 & -2.886 & $I^{* *}(2)$ \\
\hline & $\ln G D P_{i 2020}$ & 2nd & $(0,0,1)$ & -2.633 & -1.996 & -2.886 & $I^{*}(2)$ \\
\hline & $\ln G D P_{i 2020}^{2}$ & 2nd & $(0,0,1)$ & -2.956 & -1.996 & -2.886 & $I^{* *}(2)$ \\
\hline \multirow{3}{*}{ Shenzhen } & $\ln Q_{i 2020}$ & $2 \mathrm{nd}$ & $(0,0,1)$ & -2.508 & -1.996 & -2.886 & $I^{*}(2)$ \\
\hline & $\ln G D P_{i 2020}$ & 2nd & $(0,0,1)$ & -2.674 & -1.996 & -2.886 & $I^{*}(2)$ \\
\hline & $\ln G D P_{i 2020}^{2}$ & 2nd & $(0,0,1)$ & -2.903 & -1.996 & -2.886 & $I^{* *}(2)$ \\
\hline \multirow{3}{*}{ Foshan } & $\ln Q_{i 2020}$ & $1 \mathrm{st}$ & $(\mathrm{C}, 0,2)$ & -5.518 & -3.321 & -4.583 & $I^{* *}(1)$ \\
\hline & $\ln G D P_{i 2020}$ & $1 \mathrm{st}$ & $(0,0,2)$ & -2.850 & -1.996 & -2.886 & $I^{*}(1)$ \\
\hline & $\ln G D P_{i 2020}^{2}$ & $1 \mathrm{st}$ & $(0,0,2)$ & -2.674 & -1.996 & -2.886 & $I^{*}(1)$ \\
\hline \multirow{3}{*}{ Dongguan } & $\ln Q_{i 2020}$ & Zero & $(\mathrm{C}, 0,1)$ & -4.414 & -3.213 & -4.297 & $I^{* *}(0)$ \\
\hline & $\ln G D P_{i 2020}$ & Zero & $(\mathrm{C}, \mathrm{T}, 2)$ & -11.318 & -4.108 & -5.522 & $I^{* *}(0)$ \\
\hline & $\ln G D P_{i 2020}^{2}$ & Zero & $(\mathrm{C}, \mathrm{T}, 2)$ & -8.270 & -4.108 & -5.522 & $I^{* *}(0)$ \\
\hline \multirow{3}{*}{ Huizhou } & $\ln Q_{i 2020}$ & $2 n d$ & $(0,0,2)$ & -6.654 & -1.996 & -2.886 & $I^{* *}(2)$ \\
\hline & $\ln G D P_{i 2020}$ & 2nd & $(0,0,2)$ & -3.913 & -1.996 & -2.886 & $I^{* *}(2)$ \\
\hline & $\ln G D P_{i 2020}^{2}$ & 2nd & $(0,0,2)$ & -3.866 & -1.996 & -2.886 & $I^{* *}(2)$ \\
\hline \multirow{3}{*}{ Jiangmen } & $\ln Q_{i 2020}$ & 2nd & $(0,0,1)$ & -5.796 & -1.996 & -2.886 & $I^{* *}(2)$ \\
\hline & $\ln G D P_{i 2020}$ & $2 \mathrm{nd}$ & $(0,0,1)$ & -3.697 & -1.996 & -2.886 & $I^{* *}(2)$ \\
\hline & $\ln G D P_{i 2020}^{2}$ & 2nd & $(0,0,1)$ & -3.835 & -1.996 & -2.886 & $I^{* *}(2)$ \\
\hline \multirow{3}{*}{ Zhongshan } & $\ln Q_{i 2020}$ & $2 \mathrm{nd}$ & $(0,0,1)$ & -4.360 & -1.996 & -2.886 & $I^{* *}(2)$ \\
\hline & $\ln G D P_{i 2020}$ & 2nd & $(0,0,1)$ & -4.185 & -1.996 & -2.886 & $I^{* *}(2)$ \\
\hline & $\ln G D P_{i 2020}^{2}$ & $2 \mathrm{nd}$ & $(0,0,1)$ & -4.228 & -1.996 & -2.886 & $I^{* *}(2)$ \\
\hline \multirow{3}{*}{ Zhaoqing } & $\ln Q_{i 2020}$ & $2 \mathrm{nd}$ & $(0,0,1)$ & -2.817 & -1.996 & -2.886 & $I^{* *}(2)$ \\
\hline & $\ln G D P_{i 2020}$ & 2nd & $(0,0,1)$ & -3.597 & -1.996 & -2.886 & $I^{*}(2)$ \\
\hline & $\ln G D P_{i 2020}^{2}$ & 2nd & $(0,0,1)$ & -3.245 & -1.996 & -2.886 & $I^{* *}(2)$ \\
\hline \multirow{3}{*}{ Zhuhai } & $\ln Q_{i 2020}$ & $2 \mathrm{nd}$ & $(0,0,1)$ & -3.158 & -1.996 & -2.886 & $I^{* *}(2)$ \\
\hline & $\ln G D P_{i 2020}$ & 2nd & $(0,0,1)$ & -5.748 & -1.996 & -2.886 & $I^{* *}(2)$ \\
\hline & $\ln G D P_{i 2020}^{2}$ & 2nd & $(0,0,1)$ & -5.949 & -1.996 & -2.886 & $I^{* *}(2)$ \\
\hline
\end{tabular}

\section{Appendix B}

Table B.1 Unit root test results

** represents that variables passed $\mathrm{ADF}$ test at the $1 \%$ level, and * represents that variables passed

ADF test at the 5\% level. 
Table B.2 The results of Johansen Cointegration Test between $\ln Q_{i 2020}$ and explanatory variables

\begin{tabular}{ccccc}
\hline Cities & \multirow{2}{*}{ J-Statistic } & $\begin{array}{c}\mathbf{0 . 0 5} \\
\text { Critical Value }\end{array}$ & $\begin{array}{c}\mathbf{0 . 1} \\
\text { Critical Value }\end{array}$ & Prob. \\
\hline Guangzhou & 25.5572 & 24.2760 & 21.7772 & 0.0343 \\
Shenzhen & 40.7443 & 24.2760 & 21.7772 & 0.0002 \\
Foshan & 34.1228 & 24.2760 & 21.7772 & 0.0021 \\
Dongguan & 64.0706 & 24.2760 & 21.7772 & 0.0000 \\
Huizhou & 36.9750 & 24.2760 & 21.7772 & 0.0008 \\
Jiangmen & 27.3003 & 24.2760 & 21.7772 & 0.0202 \\
Zhongshan & 25.8851 & 24.2760 & 21.7772 & 0.0311 \\
Zhaoqing & 50.5797 & 24.2760 & 21.7772 & 0.0000 \\
Zhuhai & 22.2523 & 24.2760 & 21.7772 & 0.0881 \\
\hline
\end{tabular}

\section{References}

Al-E-Hashem, S.M.J.M., Baboli, A., Sazvar, Z., 2013. A stochastic aggregate production planning model in a green supply chain: considering flexible lead times, nonlinear purchase and shortage cost functions. Eur. J. Oper. Res. 230(1), 26-41.

[dataset] BSGP [Bureau of Statistics of Guangdong Province], 2017. Guangdong Statistical Yearbook 2016. China Statistics Press, Beijing. http://www.gdstats.gov.cn/tinj/2017/directory.html.

CCTN [China Carbon Trading Network], 2017. China will launch a national carbon market, how big will it be? http://www.tanpaifang.com/tanjiaoyi/2017/0818/60322.html [accessed 18 August 2017].

Chang, C.T., Lee, H.C., 2016. Taiwan's renewable energy strategy and energy-intensive industrial policy. Renew. Sustain. Energy Rev. 64, 456-465.

Chang, K., Zhang, C., Chang, H., 2016. Emissions reduction allocation and economic welfare estimation through interregional emissions trading in China: Evidence from efficiency and equity. Energy, 113, 1125-1135. 
Chen, J., Cheng, S., Song, M., Wu, Y., 2016. A carbon emissions reduction index: integrating the volume and allocation of regional emissions. Appl. Energy, 184, 1154-1164.

CSC [China State Council], 2016. 13th five year plan for controlling greenhouse gas emissions. http://www.gov.cn/zhengce/content/2016-11/04/content_5128619.htm (accessed 04 November 2016).

Fan Y., Mo J.L., Zhu L., 2016. China Carbon Market: Policy Design and Socio-economic Impact. Science Press (in Chinese).

Fang, G.C., Tian, L.X., Fu, M., Sun, M., He, Y., Lu, L.X., 2018. How to promote the development of energy-saving and emission-reduction with changing economic growth rate - a case study of China. Energy, 143, 732-45.

Han, J., Meng, X., Zhou, X., Yi, B., Liu, M., Xiang, W.N., 2016. A long-term analysis of urbanization process, landscape change, and carbon sources and sinks: a case study in China's Yangtze River delta region. J. Clean. Prod. 141, 1040-1050.

Harsanyi, J.C., Selten, R., 1972. A generalized Nash solution for two-person bargaining games with incomplete information. Manag. Sci. 18(5-Part-2), 80-106.

Hombach, L.E., Walther, G., 2015. Pareto-efficient legal regulation of the (bio) fuel market using a bi-objective optimization model. Eur. J. Oper. Res. 245(1), 286-295.

IPCC [Intergovernmental Panel on Climate Change], 2014. Climate change 2014: mitigation of climate change, contribution of working group III to the fifth assessment report of the intergovernmental panel on climate change. Cambridge, United Kingdom and New York, NY, USA: Cambridge.

Ji, J., Zhang, Z., Yang, L., 2017. Comparisons of initial carbon allowance allocation rules in an 
O2O retail supply chain with the cap-and-trade regulation. Int. J. Prod. Econ. 187, 68-84.

Jiang, N., Zhang, L.L., Yu, Y., 2017. Optimizing cooperative advertizing, profit sharing, and inventory policies in a VMI supply chain: a Nash bargaining model and hybrid algorithm. IEEE T. Eng. Manage. 62(4), 449-461.

[dataset] JNU [Jinan University], 2018. Guangdong Province Industrial Development Database. Institute of Industrial Economic Research. https://gdidd.jnu.edu.cn/page/default.aspx.

Kaika, D., Zervas, E., 2013. The Environmental Kuznets Curve (EKC) theory — part A: concept, causes and the $\mathrm{CO}_{2}$ emissions case. Energy Pol. 62(5), 1392-1402.

Konur, D., Campbell, J.F., Monfared, S.A., 2016. Economic and environmental considerations in a stochastic inventory control model with order splitting under different delivery schedules among suppliers. Omega.

Lewis, C.D., 1982. Industrial and Business Forecasting Methods: A Practical Guide to Exponential Smoothing and Curve Fitting; Butterworth Scientific, Heinemann: London, UK.

Li, T., Wang, Y., Zhao, D., 2016. Environmental Kuznets Curve in China: new evidence from dynamic panel analysis. Energy Pol. 91(2), 138-147.

Li, W., Jia, Z., 2016. The impact of emission trading scheme and the ratio of free quota: a dynamic recursive CGE model in China. Appl. Energy, 174, 1-14.

Li, W., Jia, Z., 2017. Carbon tax, emission trading, or the mixed policy: which is the most effective strategy for climate change mitigation in China?. Miti. Adapt. Strat. GL. 1-20.

Li, L., Li, Y., Ye, F., Zhang, L., 2018. Carbon dioxide emissions quotas allocation in the Pearl River Delta region: Evidence from the maximum deviation method. J. Clean. Prod. 177, 
207-217.

Liao, Z., Zhu, X., Shi, J., 2015. Case study on initial allocation of Shanghai carbon emission trading based on Shapley value. J. Clean. Prod. 105, 338-344.

Liu, H., Lin, B., 2017. Cost-based modelling of optimal emission quota allocation. J. Clean. Prod. 149, 472-484.

Liu, L., Chen, C., Zhao, Y., Zhao, E., 2015. China's carbon-emissions trading: overview, challenges and future. Renew. Sustain. Energy Rev. 49, 254-266.

[dataset] NBSC [National Bureau of Statistics of China], 2017. China Statistical Yearbook 2016. China Statistics Press, Beijing. http://www.stats.gov.cn/tjsj/ndsj/2017/indexch.htm.

Nash, J.F., 1950. The bargaining problem. Econometrica, 18(2), 155-162.

Peck, M.R., Kaina, G.S., Hazell, R.J., Isua, B., Alok, C., Paul, L., 2017. Estimating carbon stock in lowland Papua New Guinean forest: low density of large trees results in lower than global average carbon stock. Austral Ecol.

Phylipsen, G., Bode, J.W., Blok, K., Merkus, H., Metz, B., 1998. A triptych sectoral approach to burden differentiation, GHG emissions in the European bubble. Energy Pol. 26(12), 929-943.

Qin, Q., Li, X., Li, L., Zhen, W., Wei, Y.M., 2017. Air emissions perspective on energy efficiency: an empirical analysis of China's coastal areas. Appl. Energy, 185, 604-614.

Ren, F., Gu, L.H., 2016. Study on Transition of Primary Energy Structure and Carbon Emission Reduction Targets in China Based on Markov Chain Model and GM (1, 1). Math. Probl. Eng.

Salehi, M., Jalalian, M., Siar, M.M.V., 2017. Green transportation scheduling with speed control: 
trade-off between total transportation cost and carbon emission. Comput. Ind. Eng. 113.

Sartor, O., Pallière, C., Lecourt, S., 2014. Benchmark-based allocations in EU ETS Phase 3: an early assessment. Clim. Policy, 14(4), 507-524.

Sazvar, Z., Al-E-Hashem, S.M.J.M., Baboli, A., Jokar, M.R.A., 2014. A bi-objective stochastic programming model for a centralized green supply chain with deteriorating products. Int. J. Prod. Eco. 150(6), 140-154.

Song, M.L., Zhang, W., Wang, S.H., 2013. Inflection point of Environmental Kuznets Curve in mainland China. Energy Pol. 57(7), 14-20.

UNDP [United Nations Development Programme], 2015. Framework Convention on Climate Chang - adoption of the Paris Agreement. Paris, 30 November to 11 December.

Walmsley, M.R.W., Walmsley, T.G., Atkins, M.J., Kamp, P.J.J., Neale, J.R., Chand, A., 2015. Carbon emissions pinch analysis for emissions reductions in the New Zealand transport sector through to 2050. Energy, 92, 569-576.

Wang, Z., Zhu, Y., Zhu, Y., Shi, Y., 2016. Energy structure change and carbon emission trends in China. Energy, 115, 369-377.

Xia, Y., Tang, Z., 2017. The impacts of emissions accounting methods on an imperfect competitive carbon trading market. Energy, 119: 67-76.

Xiong, L., Shen, B., Qi, S., Price, L., Ye, B., 2017. The allowance mechanism of China's carbon trading pilots: a comparative analysis with schemes in EU and California. Appl. Energy, $185,1849-1859$.

Ye, F., Xie, X.X., Zhang, Li., Hu, X.L., 2018. An Improved Grey Model and Scenario Analysis for Carbon Intensity Forecasting in the Pearl River Delta Region of China. Energies, 11(1), 
91.

Zeng, S., Xu, Y., Wang, L., Chen, J., Li, Q., 2016. Forecasting the allocative efficiency of carbon emission allowance financial assets in China at the provincial level in 2020. Energies, 9(5), 329.

Zhang, Y.J., Hao, J.F., 2017. Carbon emission quota allocation among China's industrial sectors based on the equity and efficiency principles. Ann. Oper. Res. 255(1-2), 1-24.

Zhang, Y.J., Wang, A.D., Da, Y.B., 2014. Regional allocation of carbon emission quotas in China: Evidence from the Shapley value method. Energy Policy, 74(C), 454-464.

Zhao, J.Y., Hobbs, B.F., Pang, J.S., 2010. Long-run equilibrium modeling of emissions allowance allocation systems in electric power markets. Oper. Res. 58 (3), 529-548.

Zhao, X., Du, D., 2015. Forecasting carbon dioxide emissions. J. Environ. Manag. 160, 39-44.

Zhao, X.G., Li, A., 2016. A multi-objective sustainable location model for biomass power plants: case of China. Energy, 112, 1184-1193.

Zhao, X.G., Wu, L., Li, A., 2017. Research on the efficiency of carbon trading market in China. Renew. Sustain. Energy Rev. 79, 1-8.

Zhou, P., Wang, M., 2016. Carbon dioxide emissions allocation: A review. Ecol. Econ. 125, 4759.

Zhou, P., Zhang, L., Zhou, D.Q., Xia, W.J., 2013. Modeling economic performance of interprovincial $\mathrm{CO}_{2}$ emission reduction quota trading in China. Appl. Energy, 112, 1518 1528.

Zhou, W., Zhu, B., Chen, D., Zhao, F., Fei, W., 2014. How policy choice affects investment in low-carbon technology: the case of $\mathrm{CO}_{2}$, capture in indirect coal liquefaction in China. 
Energy, 73(9), 670-679.

Zhou, X., Guan, X.L., Zhang, M., Zhou, Y., Zhou, M.H., 2017a. Allocation and simulation study of carbon emission quotas among China's provinces in 2020. Environ. Sci. Pollut. Res. Int. 24(8), 7088 .

Zhou, Z., Liu, C., Zeng, X., Jiang, Y., Liu, W., 2017b. Carbon emission performance evaluation and allocation in Chinese cities. J. Clean. Prod. 